\title{
Mitochondria: Master Regulator of Metabolism, Homeostasis, Stress, Aging and Epigenetics
}

\author{
Anna Meiliana ${ }^{1,2,3, *}$, Nurrani Mustika Dewi2,3, Andi Wijaya ${ }^{2,3}$ \\ ${ }^{1}$ Department of Pharmacology and Clinical Pharmacy, Faculty of Pharmacy, Universitas Padjadjaran, Jl. Raya Bandung-Sumedang Km 21, \\ Jatinangor 45363, Indonesia \\ 2Prodia Clinical Laboratory, Jl. Supratman No 43, Bandung 40114, Indonesia \\ ${ }^{3}$ Prodia Education and Research Institute, Jl. Kramat Raya No. 150, Jakarta, 10430, Indonesia \\ *Corresponding author. E-mail: anna.meiliana@prodia.co.id
}

Received date: Jun 2, 2021; Revised date: Aug 31, 2021; Accepted date: Sep 1, 2021

\section{Abstract}

$\mathrm{B}$ ACKGROUND: Mitochondria became a driving force in evolution due to their ability to manufacture adenosine triphosphate (ATP) through respiration. The functioning of mitochondria within eukaryotic cells has evolved dramatically as a result of evolution. Recent research has revealed mitochondria form plasticity to keep the cell's needs and function.

CONTENT: Mitochondria have long been regarded as the cell's "powerhouse," providing energy for cell metabolism through oxidative phosphorylation (OXPHOS). A lot of physiological processes were known to be mediated by mitochondria including immunity and autophagy, cell death mechanism, and stem cell reprogramming. Mitochondria can change their shape to form a tubular network that is controlled by fission and fusion processes. Mitochondrial dynamics is the equilibrium between these two opposing processes that regulates mitochondrial number, size, and positioning within the cytoplasm.

SUMMARY: All of these discoveries opened up new research avenues and revealed new targets for targeted medication development. Calorie restriction, and the mimetic agents were developed to increase mitochondria biogenesis to improve human lifespan.

KEYWORDS: mitochondria, metabolism, homeostasis, stress response, aging, epigenetic

Indones Biomed J. 2021; 13(3): 221-41

\section{Introduction}

Mitochondria is largely associated with cellular bioenergetics after the discovery of the Krebs cycle in the 1950s. This perception shifted in the 1990s, when mitochondria were discovered to play a role in apoptotic cell death.(1) These led to the hypothesis that mitochondria have a role in cell signaling, which has now been confirmed by a large body of evidence where mitochondria have been linked to a number of complex cellular processes other than cell death (2), including autophagy (1), stem cell differentiation (3), and immune response regulation (4). These organelles also play a role in important metabolic processes including calcium and iron homeostasis, redox signaling, programmed cell death, and innate immunity, as well as regulating a variety of physiological processes. (5) Mitochondria are the cell's powerhouses, producing a significant portion of the cellular adenosine triphosphate (ATP) content.

Mitochondria's wide range of roles is reflected in their morphological diversity, as the outcome result of a delicate equilibrium of two opposing processes: fusion and fission. When cells exposed to mild stress, mitochondria form an elongated and interconnected network by reducing fission, resist mitophagy and increase ATP production as in nutritional deprivation. When the cells exposed to severe stress, oppositely mitochondria induce a fragmented 
form by limiting the fusion.(6) Prolonged disruption of any fusion or fission will lead to metabolism imbalance and induce many diseases such as CVD or cancer. Posttranslational modifications and protein-protein interactions control the molecular machinery that mediates organelle fission and fusion, to maintain mitochondrial integrity.(7) Mitochondria's forms, both in terms of overall size (length, breadth, and roundness) and ultrastructure (organization of mitochondrial membranes) varies in morphology between cells, throughout the cell cycle, and in response to metabolic or physiological cues.(8)

Modern day mitochondria are made up of well over 1,000 proteins, according to a combination of proteomics, genomics, and bioinformatics; the composition is plastic, varying between organisms in response to cellular and tissue-specific organismal needs.(9) Mitochondria detect and respond to a variety of stresses, and their energy production and signaling pathways may aid or hinder cell survival. Cellular stress adaption is further influenced by mitochondrial motility and inter-organellar interactions, such as those involving the endoplasmic reticulum (ER). (10) At the tissue and organismal level, mitochondrial stress responses are critical for cell fate, fitness, and disease.(11)

Many studies tried to reveal the strategies to increase human lifespan by increasing mitochondria biogenesis and keep the mitochondria quality (12), since mitochondrial dysfunction, including any alteration in mitochondrial activity cause accelerated aging (13). Calorie restriction (CR), CR mimetic agents, and exercise seems promising to restore mitochondria function. $(14,15)$

\section{Mitochondrial Quality Control}

Mitochondria are intricate organelles that house hundreds of biochemical reactions ranging from energy production to amino acid and lipid synthesis to hormone synthesis. These biochemical reactions include the flow of substrates and products between the cell's many organelles. There is growing evidence that direct interorganellar contacts are necessary for metabolite shuttling rather than free diffusion mechanisms.(16) Mitochondrial-derived vesicles (MDVs) are tiny intracellular vesicular size $70-150 \mathrm{~nm}$, carriers that carry mitochondrial proteins and lipids. Selective protein cargo incorporation, which can be limited to the outer membrane or involve the outer, inner, and matrix membranes, results in MDVs.(17) MDVs have been found to have two distinct fates, with some being directed to the late endosome/multivesicular body for degradation
(18), while others are directed to a subpopulation of peroxisomes.(17)

Cargo is delivered to peroxisomes and lysosomes via mitochondrial vesicle transport, and was eventually degraded (18), and in vitro experiments have shown that MDVs are rich in oxidized proteins (19). The purpose of vesicle delivery to the peroxisomes, however, is currently unclear. (20) Just one protein known to traffic to peroxisomes is mitochondrial-anchored protein ligase (MAPL, also known as MULAN, MUL1, GIDE, and HADES), a membraneanchored protein ligase.(17) It's difficult to predict the processes and principles that control cargo selection when there's only one known cargo.

The addition of MDV transport to lysosomes to the paradigms of mitochondrial quality control introduces a fourth mechanism as described in Figure 1. Mitophagy, mitochondrial proteases, ubiquitin-mediated proteasomal degradation, and MDVs all work together. The unanswered question is how to describe the relative contributions of these four processes and their future hierarchy. Within the matrix and intermembrane space, mitochondrial proteases degrade unfolded and oxidized proteins about $6-12 \%$ proteins per hour as a study in yeast (21), indicating that proteases are a key component of mitochondrial quality control (22). It's also conceivable that proteases trim down complexes and cargoes, leaving more hydrophobic regions to be extracted later by MDVs, which would be an example of how these pathways overlap. The loss of mitochondrial proteases causes a variety of neurological problems, including spastic paraplegia.(23)

Mitochondria use a variety of proteases to maintain their proteostasis and maintain their overall consistency. Any decline in this process induce cellular stress and accelerated aging. Thus, it needs to be tightly regulated for metabolic adaptation in a variety of physiological scenarios. Several mitochondrial proteases may be mutated or dysfunctional, resulting in complex human disorders with extreme metabolic phenotypes.(24) In each sub-compartment, a number of mitochondrial proteases (mitoproteases) provide protein quality control by destroying misfolded proteins and digesting freshly imported proteins to aid biogenesis.(25)

Mitoproteases, which function as quality-control enzymes, are likely to have an effect on metabolism because mitochondria are a central metabolic center. As a result, faulty mitoproteases play a role in a variety of human diseases, including cancer and neurodegeneration, and are closely linked to the aging process.(24) The mitophagy and ubiquitin pathways are responsible for removing dysfunctional/old mitochondria from cells via 

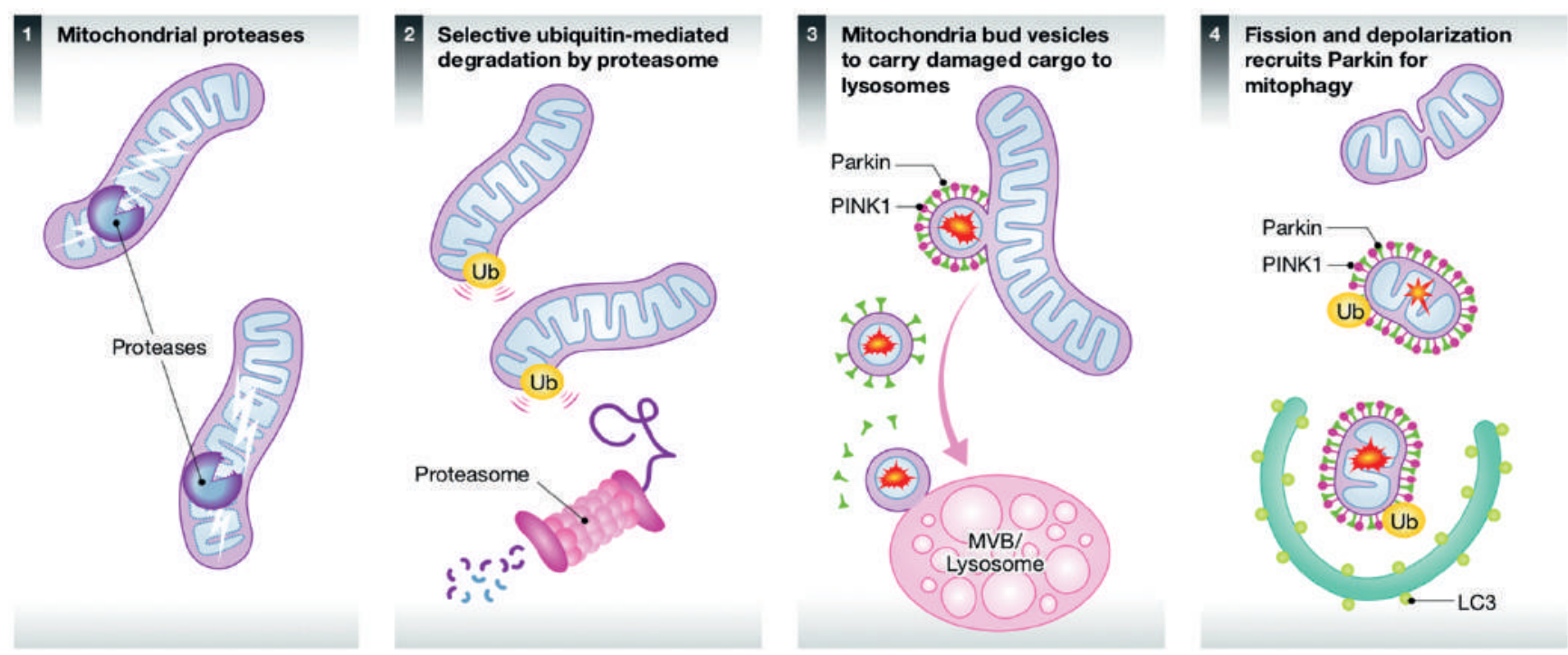

Figure 1. Outline of the 4 pathways of mitochondrial quality control.(16) (Adapted with permission from EMBO Press).

autophagy (26), and eliminating dysfunctional/misfolded proteins via the $26 \mathrm{~S}$ proteasome $(27,28)$, respectively. Healthy mitochondria and proteins are required for cells to function correctly. Because of these essential tasks, the mitophagy system governs mitochondrial quality and the ubiquitin route regulates protein quality in cells. Defects in the mitophagy or ubiquitin pathways, can disturb cellular homeostasis, placing cells at risk of dying. A number of human illnesses, including cancer, have been related to defects in the mitophagy and ubiquitin pathways.(29)

Several mitochondrial quality-control systems, including.(30) First, mitochondria preserve their quality by using their proteolytic mechanism to degrade unfolded, misfolded, or weakened membrane proteins (resulting from environmental insults such as oxidative stress, viral infections, and so on).(31) Second, when damage is mild and below a certain threshold during the fusion/fission process, compensation were done by fusion of normal and damaged mithocondrias so the protein sharing can overcome the defects.(32) Third, under oxidative stress, a portion of mitochondria will bud off and form MDVs, which then fuse with lysosomes to degrade oxidized mitochondrial proteins.(19) When mitochondria are damage, they form mitochondrial spheroids, which acquire lysosomal markers, become acidic, and conduct limited mitochondrial protein breakdown.(33) Finally, weakened mitochondria can be degraded using the ubiquitin pathway in combination with mitophagy.(26) Mitochondria have evolved sophisticated quality management systems. Mitochondrial turnover is the sum of these processes. Different macromolecules are turned over and have different half-lives within mitochondria.
Stress and developmental mechanisms influence these turnover rates.(34)

Mitophagy's opposite is mitochondrial biogenesis. De novo mitochondrial input is rare, so new mitochondrial formation needs a coordination with existing network. Furthermore, two distinct genomes must work together to create the functional multi-protein complexes needed for energy production. The nuclear-encoded mitochondrial proteins and mitochondrial transcription factor A (TFAM) for mitochondrial biogenesis were regulated by nuclear respiratory factor (NRF)1 and NRF2.(35)

Peroxisome proliferator-activated receptor gamma coactivator 1-alpha (PGC-1 $\alpha$ ), which was first identified as a transcriptional co-activator involved in brown fat thermogenesis, was discovered to stimulate NRF1 and NRF2 gene expression and trigger transcription of their downstream targets, resulting in mitochondrial biogenesis.(36) In transgenic animal models or cultured cells, overexpression of PGC-1 $\alpha$ increased mitochondrial number and function.(36,37) In mice (38) and humans (39), physiological factors such as exercise increased PGC- $1 \alpha$ levels. The loss of PGC- $1 \alpha$ had no effect on total mitochondrial volume, but it did significantly reduce mitochondrial transcript expression and reduce mitochondrial function.(40) PGC- $1 \alpha$ has been implicated in the regulation of mitochondrial efficiency and function in a number of studies.

Mitochondria have developed several quality control pathways to ensure proper operation both in the absence of stress and in the presence of it. These pathways examine the entire mitochondrial network as well as individual proteins, 
encompassing various scales of mitochondrial protein quality control.(12) Understanding how mitochondrial quality control pathways contribute to mitochondrial homeostasis may lead to the development of targeted therapies for diseases where these mechanisms fail. However, the studies to find major pathways of mitophagy has not been well understood.(34)

\section{Mitochondrial Dynamics and Metabolic Regulation}

The American architect Louis Sullivan famously said, "Form always follows purpose." He came to this conclusion after studying nature, where function is determined by well-defined structures. Mitochondria are a great example of this axiom: as they're highly plastic organelles that play key roles in a variety of cellular processes as described (41), they form the fusion which positively associated with increased ATP production (42), and fission events during the so-called 'mitochondrial life cycle' in order to meet metabolic demands and perform complex quality control, to ensure removal of damaged mitochondria (32). Linked to its function, mitochondria's morphology is dynamic. It can be dramatically changed response to metabolic inputs. (43) Mitochondrial fragmentation has been identified in cardiovascular and neuromuscular disorders, cancer, and obesity as a result of nutrient overload and cellular dysfunction. It stimulates mitochondrial autophagy (mitophagy) (11), and enables mitochondrial activities to be adapted to physiological demands (44). Figure 2 shows the machinery and context of mithochondria.
Adequate nutrient levels are essential for mitochondrial function because micronutrients including essential amino acids (EAA) and gluthatione are needed for mitochondria function and ATP-production.(45) Nutritional depletion triggers starvation and metabolic stress in cultured cells thus induce a stress-induced mitochondrial hyperfusion (SiMH) in the mitochondrial network. $(46,47)$ SiMH relies on mitochondrial fusion and the stomatin-prohibitin flotillin-HflC/K (SPFH) family scaffold protein Stomatinlike protein 2 (SLP2) to protect cells from autophagy and cell death.(46) $\mathrm{T}$ cell activation, which is dependent on mitochondrial ATP output, has been shown to be aided by SLP2.(48) This means cells lacking SLP2 have lesser respiratory chain super-complexes (RCS) which is need to efficiently improve electron transfer during OXPHOS, and cannot to expand under respiring conditions.(49) On the contrary, chronic nutritional overload increase the metabolites, including reactive oxygen species (ROS), unfolded protein responses (UPRs) by the endoplasmic reticulum (ER), and the activation of the mechanistic target of rapamycin (mTOR) which chronically cause irreversible damage to mitochondria via downregulation of adenosine monophosphate (AMP)-activated protein kinase (AMPK), and modifications to metabolic-sensitive proteins through the deactivation of sirtuins. Finally this will disrupt the metabolic homeostasis.(50)

The mitochondria are a significant mediator of environmental cues with fate decisions due to their highly dynamic existence and plasticity.(51) These metabolic shifts are followed by significant changes in mitochondrial morphology, and have been shown to influence one another during cellular processes. $(52,53)$ The metabolites produced

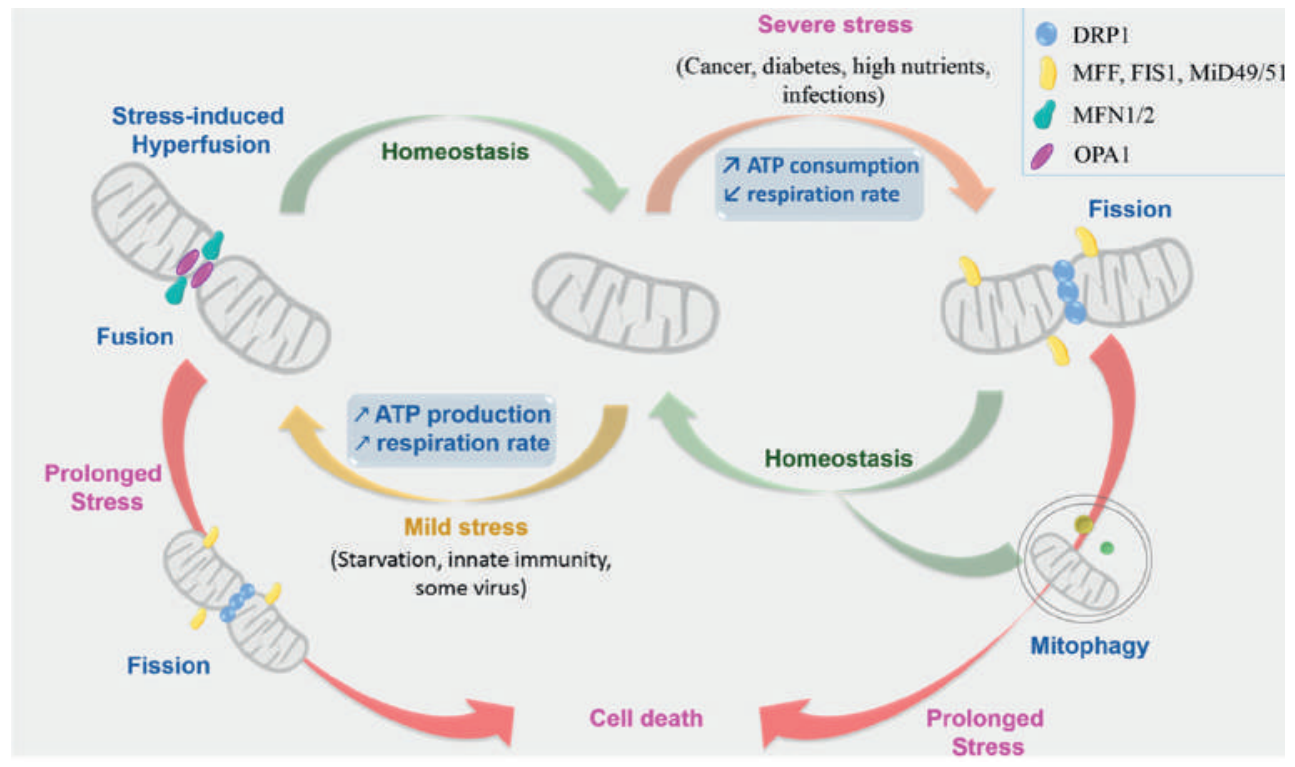

Figure 2. Mitochondrial dynamics: machinery and context.(6) (Adapted with permission from MDPI Publication). 
and metabolized in the mitochondrial tricarboxylic acid (TCA) cycle serve as cofactors for epigenetic enzymes, coupling mitochondrial metabolism and transcriptional regulation.(54) Mitochondrial dynamics in mediating the various stem cell states (pluripotent stem cells (PSC), hematopoietic stem cells (HSC), and neuronal stem cells (NSC).(43) As a result, it's possible that the direct changes in mitochondria dynamics cause metabolic reprogramming, allowing for cell fate plasticity.(54)

During cell differentiation, the transition is not linier from glycolysis to OXPHOS, as different stem cells need different requirements depend on the cell fate. This high plasticity feature is similar with mitochondrial dynamics which occur before cell transcription, indicates that they act as checkpoints for cell function integrity and plasticity.(54)

Mitofusin 1 (MFN1), Mitofusin 2 (MFN2), and OPtic Atrophy 1 (OPA1) are mitochondrial proteins that mediate fusion events in mammals (OPA1). A mitochondrion has double membrane, so the fusion occurs in two steps: the mitochondria outer membranes (MOM) provided by MFN1 and MFN2 (55), and the mitochondrial inner membranes (MIM) by OPA1. These two steps are almost simultaneous and are synchronized.

The proper ratio between two major forms of OPA1: the Long (L-OPA1) and Short (S-OPA1) isoforms is needed for mitochondrial fusion. In reality, L-OPA1 is linked to effective mitochondrial fusion, while S-OPA1 is thought to be a mediator of fission.(56) The process is catalyzed by the membrane potential-dependent protease OMA1 (metallopeptidase overlapping with the m-AAA protease1) and the ATP-dependent protease YME1L. Thus, YME1L-mediated proteolysis is responsible for OXPHOS-dependent inner-membrane fusion stimulation. Dissipation of membrane potential, on the other hand, causes OMA1 activation, followed by OPA1 cleavage and inactivation.(57) OMA1 can be activated to cleave OPA1 in response to a variety of cellular stresses.(58) Treatment with carbonyl cyanure m-chloro phénylhydrazone (CCCP) recovers fused mitochondria in cells with down-regulated OMA1 expression recovered, and become less vulnerable to staurosporine-induced apoptosis, implying that OMA1 controls the functions of the dynamin by modulating the abundance of the L-isoform.(59) This mechanism is thought to play a role in the mitochondrial fragmentation as seen in various types of mitochondrial dysfunction (60).

OPA1 has been subjected to several post-translational modifications in addition to proteolytic regulation. For examples, increased O-GlcNAcylation of OPA1 caused by high glucose exposure induces mitochondrial dysfunction in newborn cardiac myocytes via increasing mitochondrial fragmentation.(61) Sirtuin (SIRT)3, a mitochondrial deacetylase, can deacetylate OPA1 and increase its GTPase activity. Preservation of mitochondrial networking and defense of cardiomyocytes from doxorubicin-mediated cell death is aided by SIRT3-dependent activation of OPA. (62) Genetic and cell biology studies, on the other hand, have established two groups of proteins that are necessary for the mitochondrial fission process. GTPase dynaminrelated protein 1 (DRP1) (63), is thought to be the main effector of this mechanism in mammals. Given its cytosolic localization, this protein's recruitment to mitochondrial surface necessitates the presence of unique MOM adaptor proteins. Fis1, Mff, MiD49, and MiD51 are among the proteins in this second class.(64)

Apart from its role on metabolism, the mitochondrial dynamics playing a role in innate immunity, as showed by some studies that highlight mitochondrial membranes as a signaling and assembly platform. The mitochondria antiviral signaling protein (MAVS) is located on the MOM in a finite number, and causes type I interferons to be generated, resulting in downstream antiviral signaling. MAVS-driven innate antiviral signaling was decreased in a mitochondrial membrane potential-dependent manner when MFN1/2 or OPA1 was depleted.(65) It has been proposed that fusion aids MAVS aggregation by providing new molecules from different mitochondria. The NLRP3 inflammasome uses mitochondria as a signaling platform, altering mtROS, lipids, and membrane potential.(66,67) Drp1 ablation, on the other hand, may either increase or decrease NLRP3 activity, depending on the initiating stimulus.(68)

Understanding how mitochondrial fusion and fission are controlled from a molecular and biological standpoint is critical for understanding a variety of human diseases. From unpredictable organelles (69) to key biological events (70), the discovery of new players that control these events is constantly evolving, and this will continue in the coming years with the advancement of novel microscopy technology and genetic resources (71). Figure 3 shows mitochondrial structure and function, for better understanding.

\section{Mitochondrial Communication in Homeostasis}

Cellular organelles interact with one another all the time, either by establishing contact or transmitting signals. Although an organelle's core role is usually carried out in the lumen, signaling takes place at the surface. Several 
a



b

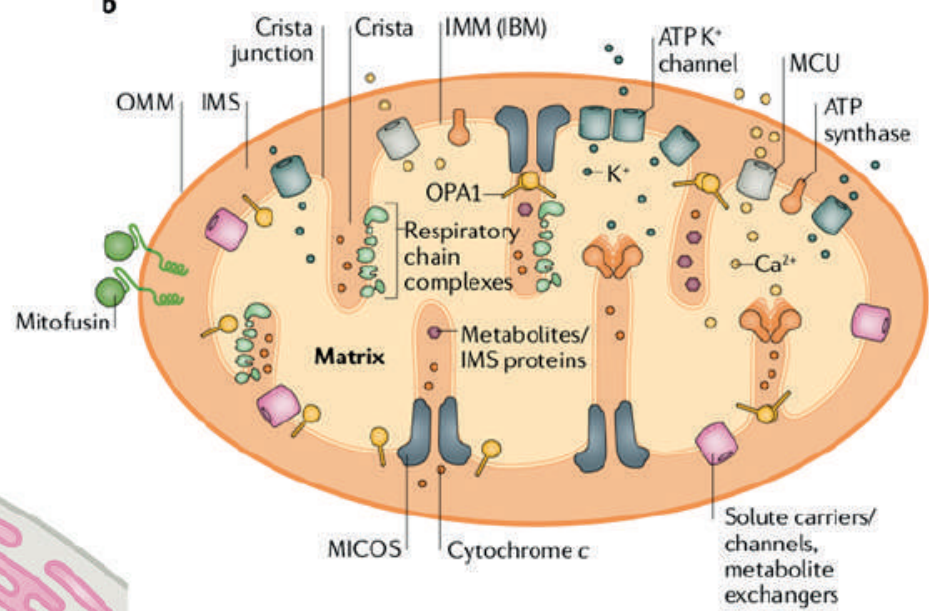

d

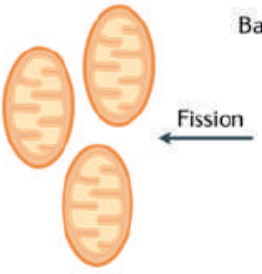

- Clearance of damaged mitochondria (mitophagy) ROS production

- Mitochondrial distribution

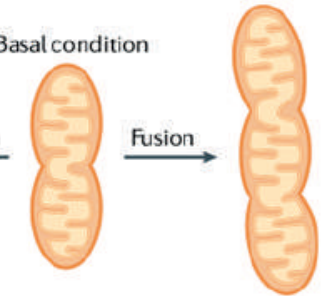

- Increased ATP production - Exchange of matrix content

Figure 3. Mitochondrial structure and function.(8) (Adapted with permission from Nature Springer).

organelles, including mitochondria (72), melanosomes (56), peroxisomes (57) and lysosomes (58), have been discovered to serve as 'launch pads' for signals to other cellular compartments, including the nucleus, in recent studies. $(73,74)$

Depending on the availability of nutrients and their ability to generate ATP, cells must actively regulate their energy intake. ATP is broken down into adenosine diphosphate (ADP), and further to AMP. Catabolic processes, such as the degradation of glucose or lipids, generate ATP, and mitochondria, the sites of OXPHOS, produce the bulk of it in cells. As cellular ATP levels drop, cells must reduce their energy consumption to avoid depleting what resources they have left. At the same time, emergency steps such as raising nutritional intake, triggering alternative energyproducing pathways, or converting existing macromolecules into nutrients must be taken to restore cellular energy supply. (75) Thus, nuclear gene expression programs regulate mitochondrial biogenesis and homeostasis, including mtDNA expression and maintenance.(76)

Mitochondria control many aspects of intermediate metabolism and being at the center of cellular energy harvesting. As a result, mitochondrial function is tightly regulated by the nucleus through a process known as 'anterograde regulation' as described in Figure 4, which can reduce or increase mitochondrial activity while also encouraging mitochondrial biogenesis, depending on cellular requirements. In contrast, mitochondria triggers produce a 'retrograde response' to then nucleus to alter cellular function and reprogram cell metabolism. Mitonuclear communication, which combines anterograde (from the nucleus to the mitochondria) and retrograde (from the mitochondria to the nucleus) signals, produces a strong network that helps cells maintain homeostasis and respond to a range of stresses.(77)

Upstream sensors that detect changes in metabolic conditions trigger these anterograde signals. As ATP synthesis is reduced, as it is during exercise and caloric restriction, the AMP/ATP ratio rises, activating AMPK, which raises cellular $\mathrm{NAD}^{+}$levels and activates SIRT1 $(78,79)$, a $\mathrm{NAD}^{+}$-dependent deacetylase which induces PGC-1 $\alpha$, stimulates the mitochondrial energy metabolism and biogenesis (80). During exercise, PGC-1 $\alpha$ is activated by increases in calcium ions $\left(\mathrm{Ca}^{2+}\right)$, either directly or indirectly via the $\mathrm{Ca}^{2+} /$ calmodulin dependent protein kinase type IV (CaMKIV) (81), or by AMPK activation after $\mathrm{Ca}^{2+} /$ 


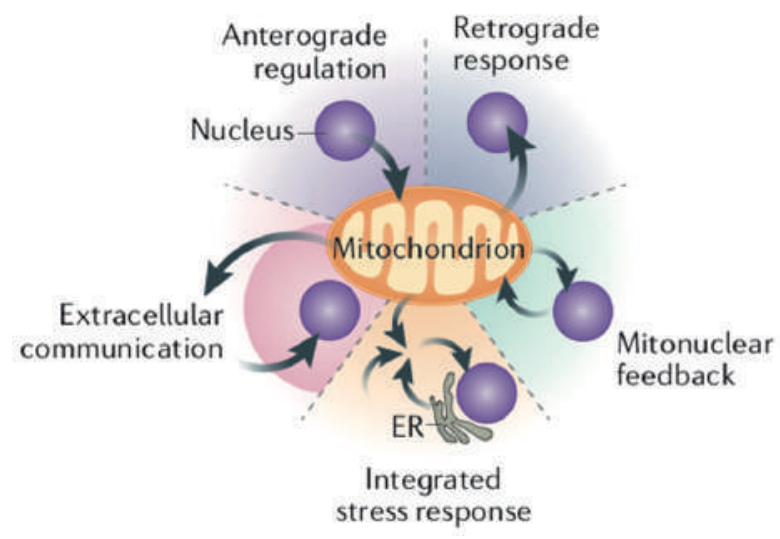

Figure 4. Mitonuclear communication.(77) (Adapted with permission from Nature Springer).

calmodulin-dependent protein kinase kinase- $\beta$ (CaMKK $\beta$ ) (82), which promotes mitochondrial biogenesis. PGC-1 is also activated by cold stress via cAMP dependent protein kinase (also known as protein kinase A (PKA)) and the cAMP response element binding protein CREB).

All organisms produce retrograde signals that regulate a variety of cellular and organismal activities as well as protect against mitochondrial dysfunction by activating nuclear genes involved in metabolic reprogramming and stress defense, but the regulation and nature of the pathways involved can differ. The pathways can be divided as energetic stress responses, $\mathrm{Ca}^{2+}$ dependent responses, and ROS stress responses, depending on the stimulus. All organisms produce retrograde signals that regulate a variety of cellular and organismal activities as well as protect against mitochondrial dysfunction by activating nuclear genes involved in metabolic reprogramming and stress defense, but the regulation and nature of the pathways involved can differ. The pathways can be divided as energetic stress responses, $\mathrm{Ca}^{2+}$ dependent responses, and ROS stress responses, depending on the stimulus.(83)

The nucleus regulates mitochondria-nucleus contact by activating several transcription factors that trigger mitochondrial genome expression, inducing transcription of several mitochondrial proteins encoded by nuclear DNA, and promoting mitochondrial adaptive pathways. Similarly, mitochondria can monitor nuclear function by regulating the levels of metabolites that influence gene expression, such as ATP, acetyl CoA, $\mathrm{NAD}^{+}$, and reactive oxygen species (ROS).(84) Protein quality control routes, mitochondrial dynamics, mitophagy, mitochondrial biogenesis, and apoptosis are only a few of the mitochondria quality control processes. $(25,85)$
AMPK can detect the amount of energy available in a cell by specifically binding adenine nucleotides in higher eukaryotes.(86) As the central integrator of mitochondrial homeostasis, and the cell's primary source of ATP, AMPK naturally has a low ATP sensor which is stimulated by changes in the ATP-to-ADP or ATP-to-AMP ratio. A lot of main proteins in multiple pathways, including mTOR complex 1 (mTORC1) (87,88), lipid homeostasis $(87,88)$, lipid homeostasis $(89,90)$, glycolysis $(91,92)$ and mitochondrial homeostasis $(93,94)$ redirects AMPK metabolism towards increased catabolism and decreased anabolism once enabled. Control of mitochondrial number via mitochondrial biogenesis stimulation, regulation of the form of the mitochondrial network in cells, and mitochondrial quality control via autophagy and mitophagy regulation are all examples of these aspects.(75)

Calcium is a versatile signaling ion that has been connected to wide range of processes, including fertilization, muscle contraction, and cell death. It's been nicknamed as the life and death signal for good reason.(95) Mitochondria are one of the most important calcium signaling regulators and targets (96), since mitochondria involved in many basal and adaptive physiological respons (97).

The transcription factor NF-E2 p45-related factor 2 (Nrf2) is mainly regulated at the level of protein stability to controls the expression of the genes network that code for proteins of cytoprotective properties. Nrf2 is a shortlived protein that undergoes continuous ubiquitination and proteasomal degradation in its natural state. The degradation of Nrf2 is aided by three different ubiquitin ligase systems. (98) Nrf2 functions as a master regulator of cellular redox homeostasis (99), and has a direct transcriptional target in the $\mathrm{xCT}$ subunit of system $\mathrm{x}-\mathrm{c}$, which imports cystine into cells (100).

Cysteine is converted to cysteine in the cell, which is a precursor for GSH production. Nrf2 ensures that glutathione remains in its reduced state by coordinating transcriptional control of glutathione reductase 1 , which converts oxidized glutathione to GSH utilizing NADPH reducing equivalents. Malic enzyme 1 (ME1), isocitrate dehydrogenase 1 (IDH1), glucose-6-phosphate dehydrogenase (G6PD), and 6-phosphogluconate dehydrogenase (PGD) are the four main NADPH-generating enzymes, which transcriptionally controlled by Nrf2 (101), and so do the inducible gene expression of cytosolic, microsomal, and mitochondrial aldehyde dehydrogenases (102), which employ NAD(P) as a cofactor to produce NAD(P)H.

As a result, when compared to WT, the total mitochondrial NADH pool in Keap1-KO cells is 
substantially higher, whereas it is dramatically lower in Nrf2-KO cells.(103) Nrf2 is important for mitochondrial integrity, especially in redox homeostasis. Mitochondria from the brain and liver of rats given a single dose of the Nrf2 activator sulforaphane are immune to the oxidant tertbutylhydroperoxide opening the mitochondrial permeability transfer pore (mPTP).(104) Mitochondrial behavior evolves in respond to stress and other endomembrane compartments status, such as endoplasmic reticulum.(64)

\section{Mitochondria as Regulator of Cellular Stress Response and Apoptosis}

Stressors can be chemical or physical in nature, and their frequency can be acute or chronic. Mitochondria are essential for the removal of cells that have been fatally compromised by stressors that surpass the cell's adaptive ability such as genetic alterations in mitochondrial and nuclear DNA genes (mtDNA and nDNA genes, respectively) that encode over 1,000 mitochondrial proteins, including the mtDNA maintenance machinery.(11) Even some stressors which is not targeting mitochondria still affect the mitochondrion, since it involves in critical process for cell's survival against the stressors.(105) Other stressors, such as oxidative phosphorylation, intermediate metabolism, cell death, calcium signaling, or cell dynamics, specifically target and interfere with mitochondrial function.(11)

Mitochondrial stress may also be caused by a lack of mitochondrial fuel substrates or an excess of nutrients such as glucose and fatty acids results from High Fat Diet (HFD).(43) Stressors include disruptions of intracellular iron (106) and calcium $\left(\mathrm{Ca}^{2+}\right)$ homeostasis, such as prolonged stimulation with $\mathrm{Ca}^{2+}$-linked agonists, inadequate cytoplasmic $\mathrm{Ca}^{2+}$ clearance, and reduced mitochondrial $\mathrm{Ca}^{2+}$ gatekeeping $(107,108)$. The respiratory chain produces more ROS as a result of various stressors, with mitochondria being a major source of ROS and a target of ROS-mediated injury.(109) Stressors that disrupt fusion/fission cause mitochondrial shapes to become more complex. By fusing the two ends of tubular mitochondria, hypoxia-reoxygenation and other stressors may cause donut-shaped mitochondria. Matrix expansion induced by the opening of the permeability transition pore (PTP) or the $\mathrm{K}+$ channel in $\mathrm{H} 9 \mathrm{c} 2$ cells is followed by partial detachment from the microtubular track. The formation of donuts is a stress response that can protect the body from structural damage caused by swelling.(110)

Adaptive and maladaptive stress responses are possible. Maladaptive effects contribute to stress pathophysiology and disease state growth, while adaptive effects contribute to resilience. When adaptation wears out and maladaptation takes over, the organism moves from physiology to pathology. We classify three types of stressors based on initiation and length that trigger various stress response patterns: early onset, chronic; late onset, acute; and late onset, chronic.(10)

In order to preserve homeostasis, the cell activates defensive mechanisms in stressful situations. The developed stress responses, either result in a positive event that counteracts the environmental attack, or in cell death if they fail.(6) Some selective mild stresses, such as UV irradiation, RNA transcription inhibition, protein translation inhibition, and moderate nutrient starvation, activate the so-called SIMH response in this context and in various cell models. The SIMH requires the MFN 1 and OPA1 fusion machinery proteins, as well as the MIM protein SLP2. Since it is linked to increased ATP production and NF-activation, SIMH is thought to be a pro-survival response to stress. $(46,111)$

Proteostasis is a mechanism of protein homeostasis control, including the development, folding, and degradation, for cellular survival. Unfolded protein responses (UPRs), which are finely organized and involve close contact with the nucleus, have developed in the cytosol, ER, and mitochondria to maintain proteostasis in different subcellular compartments. Proteostasis dysfunction is linked to protein aggregation and is seen in a number of age-related diseases. (112) Although the UPRER and the cytosolic heat shock response (HSR) have been extensively studied $(113,114)$, the mitochondrial unfolded protein response (UPRmt) is a relatively new discovery that sheds light on the nucleusmitochondrial relationship $(115,116)$.

Different stress factors, such as the UPRER, the UPRmt, oxidative stress, nutritional deficiency, the presence of viral double-stranded RNA, or haem deficiencies, cause mitochondrial stress and induce integrated stress response (ISR).(117,118) The eukaryotic translation initiation factor 2 (eIF2 $\alpha$ ) subunit is a key component of this stress response. Phosphorylation of eIF2 by many different kinases, such as general control nonderepressible 2 (GCN2), PKRlike ER kinase, protein kinase double stranded RNA-dependent or haem-regulated inhibitor, inhibits protein synthesis globally while facilitating the particular expression of stress response genes like ATF4.(119,120) ATF4 promotes the production of a number of stress proteins, including $\mathrm{CHOP}$, growth arrest and DNA damage-inducible protein 34 (GADD34), ATF3, immunoglobulin heavy chain binding protein (BIP; also known as GRP78), and tribbles homologue 3 (TH3), to restore appropriate cellular function (TRIB3).(117) 
Mitochondrial stress signals not only induce various cellular responses, but also non-cell autonomous responses (Figure 5), meaning that mitokines can be secreted from stressed mitochondrial cells. Mitonuclear stress induced by tissue-specific knockdown of ETC subunits can be transmitted to distant tissues in C. elegans; when mitonuclear signaling was selectively induced in neurons by neuronspecific knockdown of cco1, the UPRmt was activated not only in the nervous system but also in the intestine, with a beneficial effect on the entire organism, including an increase in lifespan.(121)

Certain cells inside our bodies must die in order for us to survive. Damaged, dysfunctional, or no longer needed cells are constantly cleared through controlled cell death and ideally replaced by new, healthy cells to maintain normal physiology and tissue function. $(122,123)$ When these natural cell death processes go wrong, the results can be tragic. Excessive or incomplete cell removal can induce many diseases such as neurodegenerative, cardiovascular, autoimmune, and infectious diseases. $(124,125)$

Apoptosis is needed for proper development $(126,127)$, tissue homeostasis $(128,129)$ and cancer prevention in vertebrates (130). Apoptotic cell death is characterized by a number of similarities, culminating in the activation of cysteine-aspartic proteases (caspases), which degrade cellular components in order to prepare dying cells for phagocyte clearance with minimal stress to surrounding cells and tissues.(131) In comparison to necrosis (an uncontrolled type of cell death often resulting from acute cell trauma), (132), apoptosis is an active process that requires energy input. Apoptosis is caused by pro-apoptotic, BH3-only proteins, which get their name from the fact that they only have $\mathrm{BH} 3$ domain. The $\mathrm{BH} 3$-only 'activator' proteins are the main effectors of apoptosis commitment: BCL-2-interacting mediator of cell death (BIM), which is encoded by BCL; BH3-interacting domain death agonist (BID), which is encoded by BID; p53-upregulated modulator of apoptosis (PUMA), which is encoded by $\mathrm{BBC} 3$; and possibly others that bind and activate one or both of the pro-apoptotic pore-forming proteins. BCL-2 antagonist/killer (BAK), encoded by BAK1, or BCL-2 associated X protein (BAX), encoded by BAX. When BAX or BAK are activated at the mitochondrial surface, they undergo an allosteric transition, allowing them to oligomerize and form macropores in the outer membrane, causing permeabilization of the mitochondrial outer membrane (MOMP) (Figure 6).(133)

In apoptosis, MOMP is triggered by effector proapoptotic members of the B cell lymphoma 2 (BCL2) family of proteins (most notably BAX and BAK), initiates a signaling cascade that leads to cell death; however, as we have now learned, induction of MOMP is not synonymous with cell death. MOMP also has other effects in addition to cell death, such as the activation of proinflammatory signaling. Finally, although apoptosis is the most common form of controlled cell death, it is far from the only one. Necroptosis, pyroptosis, and ferroptosis are three forms of controlled cell death that have only recently been discovered. Mitochondria have been implicated in these additional modalities of controlled cell death, but their functions are still unclear and tend to be less prominent.(134)



Figure 5. The integrated stress response.(77) (Adapted with permission from Nature Springer). 


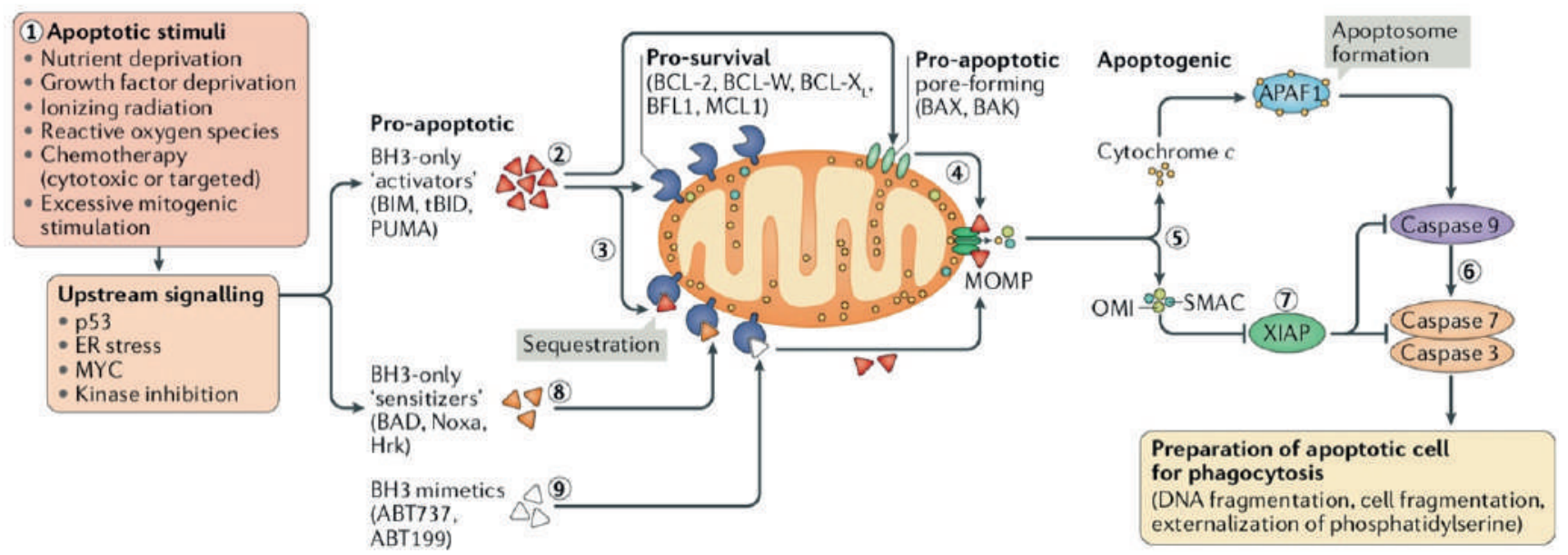

Figure 6. The mitochondrial apoptosis pathway.(133) (Adapted with permission from Nature Springer).

From a strictly mitochondrial perspective, mitochondria are the most important organelles in deciding cell fate. Indeed, mitochondria determine whether a cell survives or dies. They are key regulators of apoptosis as well as participating in various critical biosynthetic and metabolic pathways, as well as calcium and redox homeostasis.(135)

\section{Mitochondrial Dysfunction in Aging}

One of the hallmark of ageing and accelerated aging is mitochondrial dysfunction, including any alteration in mitochondrial activity. $(13,136)$ Thus, increased mitochondrial ROS has a direct link to longevity.(136) UPRmt suggested to promote lifespan by an initiation to nuclear retrograde pathway.(137)

One of the keystones driving evolution is the ability to recognize, react to, and adapt to diverse environmental stresses through cellular level defensive mechanisms that protect the entire organism and maintain its potential to grow and reproduce.(138) Stress adaptation and aging are known to be intimately linked.(139) The idea are linked stems from research in model organisms, where the discovery of aging-related molecular pathways, insulin/insulin-like growth factor (IGF), sirtuins, TOR, and AMPK, revealed that intrinsic activation of stress protection programs and the resulting adaptation would extend life expectancy (140), while suppressing the insulin/IGF-1 signaling in worms and mice promotes their lifespan (141). It became evident over time that exposing people to moderate levels of stress could trigger beneficial and adaptive stress response pathways, enabling them to live longer (142), it is now called 'hormetic stress response,' which piqued the scientific community's attention because of its possible use in the pharmacological treatment of age-related diseases. $(116,143)$

Mitoproteases play a main role in recycling the misfolding and damaged protein, as well as importing proteins for mitochondria gene expression, as part of mitochondria quality control.(144) This enzyme performs highly regulated mitochondrial dynamics via proteolytic reactions, either mediating proteolytic processing or deciding the half-lives of short-lived regulating proteins. $(25,145)$ Impaired or dysregulated activity of mitochondrial proteolysis has been linked to a variety of diseases, including cancer, metabolic syndromes, and neurodegenerative diseases (146) and the control of ageing and longevity (13). Mitochondrial function deteriorates as people get older, and this deterioration is followed by a drop in mtDNA and protein levels, a decrease in mitochondrial mass, a reduction in respiration, and significant changes in mitochondrial morphology. Mitoproteases are involved in the regulation of mitochondrial proteostasis, so it's possible that mutations in these enzymes play a role in the mitochondrial dysfunction seen as people age. $(147,148)$

The molecular hallmarks of senescence cells including the resistance to apoptosis, morphological and structural changes, epigenetic changes, chromatin rearrangement, and a changed transcriptome program. $(149,150)$ Senescent cells also contain a complex mix of secreted factors called the SASP $(149,151)$, which induces the secretion of many proinflammatory cytokines including interleukins, chemokines, growth factors, proteases, cell surface molecules, and extracellular matrix degrading proteins via the transcription factor NF- $\mathrm{KB}$ (152). Mitochondria have been identified as a key modulator in the development of the senescence phenotype, especially the pro-inflammatory 
SASP.(153) Telomere attrition, as well as other telomereindependent factors such as oxidative stress, activated oncogenes (also known as oncogene mediated senescence/ OIS), irradiation, genotoxic drugs, cell-cell fusion, epigenetic modifiers, or disrupted proteostasis, have all been identified as potent inducers of cell senescence. Senescence can also be caused by a failure to repair DNA damage.(154) In vitro study showed that mtDNA-depleted cells exhibit senescent phenotypes such as resistance to cell death, increased SA- $\beta$-gal activity, and lipofuscin accumulation, suggests that mtDNA damage can play a role in cellular senescence.(155) Many nuclear-derived transcription factors including DNA polymerase $\gamma$ (POL $\gamma)$, PGC-1 $\alpha$, NRF-1/2, SIRT and TFAM that control mitochondrial biogenesis also have roles in cellular senescence.(156) Inefficient mitochondrial genome's integrity maintenance cause defects/errors in the mtDNA replication machinery and/or failure in the repair of mtDNA damage. This results in impaired mitochondrial biogenesis, mitochondrial malfunction, and cell bioenergetic failure.(157)

The coordinated action of two genomes: nuclear and mitochondrial, is needed for mammalian mitochondria biogenesis and function.(158) Nucleoids are protein DNA complexes that include MtDNA. $(159,160)$ The mitochondrial transcription factor A (TFAM), is the key DNA packaging protein of nucleoids. $(161,162)$ The NRF1 and 2 genes, which are involved in the transcriptional control of mtDNA, the PGC1 $\alpha$ gene, which stimulates mitochondrial biogenesis as a basis for cellular energy metabolism regulation, and SIRT (156), are all essential in maintaining the mitochondrial genome's integrity. In mitochondria, SIRT3, SIRT4, and SIRT5 are NAD+-dependent deacetylases, deacylases, and ADP-ribosyl transferases. The metabolic status of the cell is indirectly connected to their enzymatic activity (through NAD+). They help maintain mitochondrial homeostasis during stressful conditions by regulating non-metabolic elements of mitochondrial function.(163)

\section{Mitochondria: Master of Epigenetics}

Metabolites operate as cofactors and regulators for a variety of enzymes, including those involved in chromatin remodeling. As a result, metabolic activities have been found to influence covalent modifications of DNA and histones, such as methylation, hydroxylation, acetylation, crotonylation, $\beta$-hydroxybutyrylation, 2-hydroxyisobutyrylation, O-GlcNAcylation, and poly(ADP) ribosylation (PARylation), with consequent impacts on gene expression.(164) Methylation is a fundamental chromatin alteration that is intimately linked to metabolism. DNA methyltransferases (DNMTs), lysine methyltransferases (KMTs), and peptidyl-arginine methyltransferases (PRMTs) are some methyltransferases role in epigenetic gene regulation.(165) These enzymes deposit methyl groups on DNA and histones, causing chromatin accessibility, transcription factor binding, and gene expression to alter dramatically.(166)

All creatures rely on dynamic gene expression regulation in response to changing local conditions to survive. The establishment of functionally diverse cell lineages in metazoans is based on the coordination of gene expression programs. Many of the chemical modifications that adorn DNA and histones are adducts formed by cellular metabolic pathway intermediates. Furthermore, metabolites are used by many enzymes that can destroy these marks as part of their enzymatic reaction. These findings lead to the notion that metabolite levels have an impact on the deposition and removal of chromatin modifications.(167)

Metazoan creatures have a more complicated nutrient signaling system than prokaryotes. Signaling pathways have evolved in multicellular organisms to react to specific nutrients as well as hormones that indicate metabolic status. (168) The response of an individual cell to such extracellular signals (e.g., whether to rewire metabolic pathways to favor an anabolic vs. catabolic state) is influenced by a number of intracellular nutrient and bioenergetic sensors such as AMPK, mTOR, and GCN2. These enzymes detect variations in intracellular metabolites and transform them into an output, substrate phosphorylation, which can occur at any ATP/ADP ratio found in viable cells. These signaling channels work together to allow cells to synchronize organismal metabolic status with intracellular metabolic status (through extracellular signaling pathways). Furthermore, these kinases enable metazoan organisms to modify gene expression in response to a wide range of substrates necessary to sustain bioenergetics. Suggest that mitochondrial metabolism and the epigenome are linked. $(51,167,169)$

Terminally differentiated cells, unlike stem cells which have a fragmented mitochondrial network (170), is rely on the mitochondria for bioenergetic demands by using OXPHOS, a process of energy generation fueled by respiration, and the ETC, which is characterized by a hyperfused mitochondrial network essential for OXPHOS operation (171). The metabolic shifting between OXPHOS and glycolysis is facilitated by mechanisms that balance mitochondrial clearance and mitochondrial biogenesis, 
dictating stem cell outcomes. As a result, the efficiency of reprogramming somatic cells to iPSC decreased, as did mitochondrial mass and mtDNA levels.(172) These findings highlight the importance of metabolic reprogramming as a driving force in stem cell fate outcomes before nuclear identity is established, which is also controlled by mitochondrial homeostasis mechanisms and posttranslational modifications, ensuring high metabolic plasticity when needed.(54)

The mitochondrial pyruvate carrier is found in the MIM and is required for effective mitochondrial pyruvate absorption as well as the link between glycolysis and the TCA cycle.(173,174) In glycolytic cancer cells and intestinal stem cells, overexpression of mitochondrial pyruvate carrier was reported to decrease proliferation and self-renewal capacity.(175,176) Epigenetic processes maintain the dynamic nature of chromatin, allowing for cellular plasticity. The research of metabolism-driven chromatin regulation, particularly in PSC, has risen in prominence in recent years because cellular metabolism provides essential metabolites for direct control of DNA and histone modifications, as well as cofactors and allosteric inhibitors of epigenetic enzymes. In pioneering research in this field, the necessity of metabolic regulation for the survival of mouse ESC in vitro was initially established. (177) Surprisingly, the finding that ESC was significantly reliant on one key amino acid, threonine, was discovered using culture medium depleted of each of the 20 amino acids separately. During the undifferentiated condition, TDH, which converts threonine to glycine, and Ac-CoA were also shown to be expressed exclusively in undifferentiated ESC and explanted blastocyst embryos.(177)

The nuclear levels of the key metabolite Ac-CoA, which are in line with the enzymatic activity of histone acetyl transferase and histone deacetylase, dictate global histone acetylation levels. Early PSC differentiation is mediated by glycolysis-derived Ac-CoA regulation of histone acetylation levels. Histone acetylation decreases with spontaneous differentiation of PSC, due to decreased glycolytic flux, and lower amounts of Ac-CoA produced. Exogenous acetate, a precursor for Ac-CoA synthesis, prevented PSC escape from pluripotency during differentiating by inhibiting histone deacetylation. Surprisingly, the necessity of maintaining a high glycolytic flux during PSC self-renewal is owing to glycolysis' connection to the TCA cycle and the production of pyruvate-derived Ac-CoA, rather than the traditional uncoupling Warburg effect.(178,179).

Because Ac-CoA cannot freely diffuse from the mitochondria, cytosolic and nuclear Ac-CoA pools rely on mitochondria-derived citrate efflux. The enzyme ATP citrate lyase (ACLY) degrades citrate to produce extramitochondrial Ac-CoA and oxaloacetate.(180) Silencing of ACLY results in decreased levels of histone acetylation, reduced glucose intake and decreased glycolytic enzyme expression, which can be rescued by adding exogenous acetate, a precursor for histone acetylation in the absence of Ac-CoA.(181) However, in case of cancer, ACLY silencing lower levels of histone acetylation in the cells and lowered lipid buildup in adipocytes that were differentiating.(181) ACLY appears to relate cellular metabolism, particularly glucose-derived AcCoA, with histone acetylation and cell outcomes, according to these research.(54)

TCA cycle metabolites serve as cofactors for epigenetic enzymes, which is the most well-studied path for contact between the mitochondria and the nucleus. As previously described, some mitochondrial enzymes (e.g., $\mathrm{PDH}$ ) have been shown to localize to the nucleus and thus produce metabolites (Ac-CoA) close to the regulatory sites (histone acetylation).(138) If it is possible that a single mitochondria could reach the nucleus and transport the entire mitochondrial enzymatic machinery, the nucleus may be in charge of the creation and distribution of several mitochondrial metabolites. This would eliminate the need to recreate the mitochondrial enzymatic network in the nucleus from scratch.

\section{Strategies to Restrore Mitochondrial Function}

Disruptions in mitochondrial bioenergetic and metabolic function can cause a variety of secondary mitochondrial diseases.(182,183) Mitochondrial disorders are caused by abnormal ROS production, calcium dyshomeostasis, defective mitochondrial biogenesis, disruption of mitochondrial dynamics and quality control, necrotic cell death induced by the MPTP, inappropriate activation or suppression of apoptosis, lowered cellular ATP:ADP ratio, decreased $\mathrm{NAD}^{+}$levels, and changes in mitochondrial signaling pathways.(183) These various types of organelle dysfunction are frequently found together because they are mechanistically related, and they can contribute to disease through acute, irreversible cell death, long-term disruption of mitochondria's role as signaling hubs, or lifelong accumulation of environmental damage that leads to a degenerative disorder.(184,185)

In summary, there are three reasons why mitochondria should be pursued as a therapeutic target for common 
diseases. First, many common diseases are secondary mitochondrial disorders, meaning that mitochondrial dysfunction plays a role in the disease process or progression. As a result, focusing on the organelle can enhance patient outcomes, even though mitochondrial dysfunction isn't the primary cause of disease. Second, mitochondria are involved in a variety of pathologies through common pathways $(183,186)$, so a single therapeutic method could be used to treat multiple disorders. Finally, in our aging population, the common diseases where targeting mitochondria shows promise are having a rising medical, societal, and economic impact. New approaches are needed because the creation of new medications for these disorders has been frustratingly slow.(187)

The mitochondrial response during $\mathrm{CR}$ is based on PGC-1 $\alpha$-dependent pathways, as well as SIRTs and AMPK activity (CR). PGC- $1 \alpha$ is expressed and activated under $\mathrm{CR}$ conditions, resulting in an increase in mitochondrial biogenesis through coactivators like NRF1 and NRF2 (Figure 7). PGC-1 $\alpha$ gene expression did not decrease with age in $\mathrm{CR}$ models, implying that $\mathrm{CR}$ animals maintain mitochondrial biogenesis better.(188,189) CR also affects bioenergetic sensors including the AMP/ATP and $\mathrm{NAD}^{+} /$ NADH ratios, which activates AMPK and SIRT1, two of the most essential mitochondrial biogenesis regulators. It has been established that starvation induces AMPK expression and that its activation triggers a signaling cascade that increases PGC-1 $\alpha$, thereby enhancing mitochondrial biogenesis.(190) However, activating AMPK in the absence of SIRT1 has no effect on mitochondrial function and cancels out the benefits of CR.(191) SIRT3's function in mitochondrial physiology has been linked to that of other members of the SIRT family. SIRT3 actually increases under CR conditions, implying that its regulation is influenced by caloric intake.(192) SIRT1 and SIRT3 have also been linked to mitochondrial biogenesis during $\mathrm{CR}$ by activating NO synthase (NOS) and PGC-1, which, when coupled with mitophagy activation via factor forkhead box O-3 (FOXO3) deacetylation, enhances mitochondrial restoration. $(14,15)$

$\mathrm{CR}$ reduces oxidative stress and stimulates the proliferation of mitochondria through a peroxisome
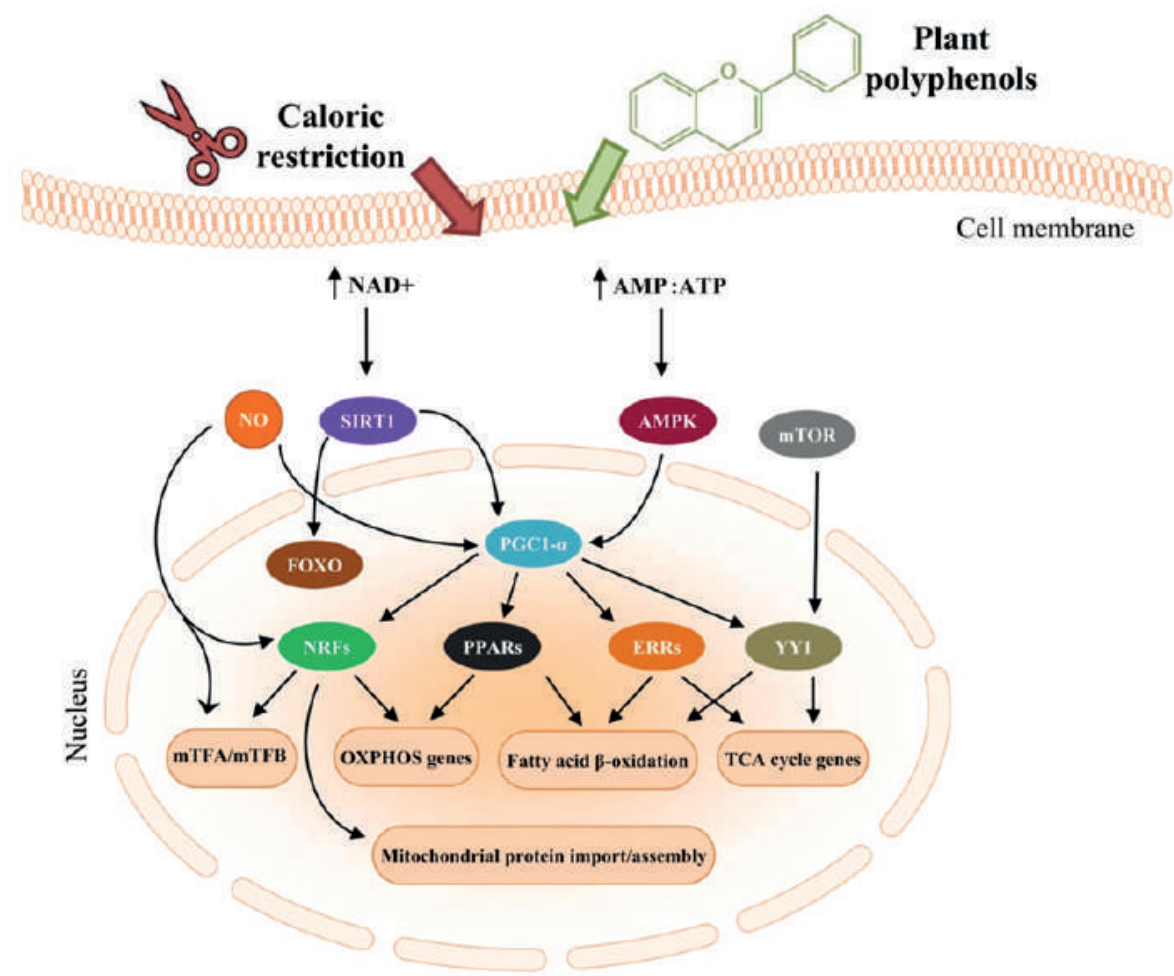

Cell membrane

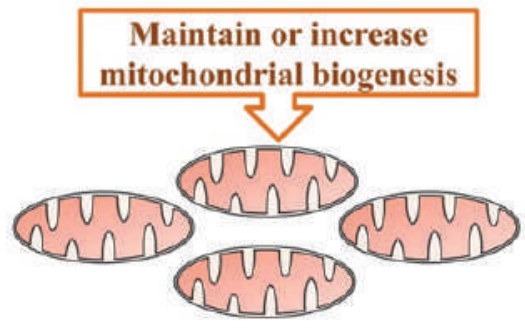

Figure 7. Key players involved in mitochondrial biogenesis.(15) (Adapted with permission from Elsevier). 
proliferation-activated receptor coactivator $1 \alpha$ signaling pathway.(193) Hancock et al reported that three months of $30 \% \mathrm{CR}$ results in large increases in mitochondrial biogenesis in heart, brain, liver, and adipose tissue, as well as ATP synthesis increases (194), thus chronic CR mitigates many detrimental effects of aging and prolongs lifespan (195).

There are several opportunities to interfere. SIRTs are influenced by transcription, translation, protein stability, and oxidative stress so then they are involved in many process from energy metabolism, cell survival, DNA repair, tissue regeneration, as well as inflammation, neuronal signaling, and even circadian rhythms. SIRTs are additionally influenced by protein-protein interactions, natural inhibitors such as nicotinamide, microRNAs, cell and organelle location, and the availability of substrate and co-substrate.(196) The mammalian SIRTs: SIRT1, SIRT6, and SIRT7 operate as transcription regulators in the same way that the yeast SIRTs do.(23,197) SIRT1, a nuclear protein, deacetylates histones H3, H4, and H1 $(197,198)$ as well as more than 50 non-histone proteins (199), such as transcription factors and DNA repair proteins. The

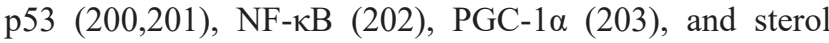
regulatory element-binding protein (SREBP) are some of the transcription factors controlled by SIRT1 (204).

$\mathrm{NAD}^{+}$is transformed to nicotinamide (NAM) and O-acetyl-ADP-ribose during sirtuin-mediated deacetylation of target Lys residues.(205) By binding to the C-pocket of SIRTs, which is adjacent to the NAD $\mathrm{NA}^{+}$-binding pocket, NAM acts as a SIRT inhibitor.(206,207) NAM is still one of the most popular and efficient SIRT inhibitors. NAM and its methylated metabolite 1-methyl-nicotinamide (MNA) have also been linked to health in recent studies. More than a decade ago, scientists began looking for chemicals that activate SIRTs. Many of the obstacles to the production of STACs as medicines have been resolved in the last three years, including technological problems, increasing STAC bioavailability, and deciding the diseases to prioritize in clinical trials.

The first SIRT1 STACs were found in 2003, with resveratrol being the most powerful in promoting SIRT1mediated deacetylation of PGC- $1 \alpha$, hence stimulating PGC-1 transcriptional activity in mice and rats' neurons, liver, and muscles. This discovery was significant since it demonstrated that SIRTs might be activated allosterically. (208) More than 14,000 STACs from a dozen chemical groups have been detected as a result of high-throughput screening and medicinal chemical efforts, including stilbenes (for example, resveratrol), chalcones (for example, butein), and flavones (for example, quercetin) from plants. (208) Imidazothiazoles (for example, SRT1720) (209), thiazolopyridines (for example, STAC-2), benzimidazoles (for example, STAC-5) and bridged ureas (for example, STAC-9) are all examples of synthetic STACs) $(210,211)$. Via a K-type allosteric activation mechanism, both of these chemical groups activate SIRT1 by lowering the substrate's Km value.(212) Quercetin, curcumin, myricitrin, ellagitannin, and epigallocatechin-3-gallate (EGCG) are a few examples of polyphenols that enhance mitochondrial biogenesis. Resveratrol, on the other hand, is a well-known polyphenol that may be utilized to imitate CR and increase mitochondrial biogenesis $(213,214)$ through multiple mechanisms, including modulation of PGC-1 $\alpha$, SIRT1, mTOR, ERR- $\alpha$, and AMPK $(215,216)$. Resveratrol increased NO development by inducing mitochondrial biogenesis via a process involving the Nrf2 signaling pathway. It also mimics calorie restriction by inhibiting cAMP phosphodiesterases (PDEs) (Figure 8). In SH-SY5Y neuroblastoma cells treated with resveratrol, crosstalk between AMPK and Nrf2 about mitochondrial biogenesis and cellular redox maintenance. $(217,218)$. Several sessions of exercise also activates SIRT1 and SIRT3. Together with the biogenesis and mitochondrial oxidative function, these will activate ATP production and the mitochondrial function.(219)

NAD is now known to be a substrate for many enzymes involved in signal transduction, DNA damage repair, epigenetics, and metabolic control, in addition to being a cofactor for various redox enzymes. $(220,221)$ Nearly two decades ago, the revelation that $\mathrm{NAD}^{+}$was a substrate for the SIRT family of deacetylases reignited interest and excitement in the area, resulting in significant breakthroughs in our understanding of the biology and metabolism of this nucleotide.(221) $\mathrm{NAD}^{+}$levels decline in physiological conditions such as aging and pathological diseases impacting numerous organ systems such as skeletal muscle, heart, kidney, central nervous system, and eyes. (220) Thus, animal studies suggest that dysregulation of NAD metabolism is a common feature of different states (220), and that restoring NAD + levels during aging and numerous rodent illness models improves health and alleviates pathological conditions.(222)

$\mathrm{NAD}^{+}$levels can be raised by either boosting $\mathrm{NAD}^{+}$ production enzymes or administering $\mathrm{NAD}^{+}$precursor molecules, or by restricting its use. $\mathrm{NAD}^{+}$content can be increased by supplementing with NA, NAM, NR, NMN, or tryptophan (223), or by activating enzymes that catalyzes the rate-limiting steps of $\mathrm{NAD}^{+}$biosynthesis $(224,225)$. Although there is no guarantee that increasing $\mathrm{NAD}^{+}$will 


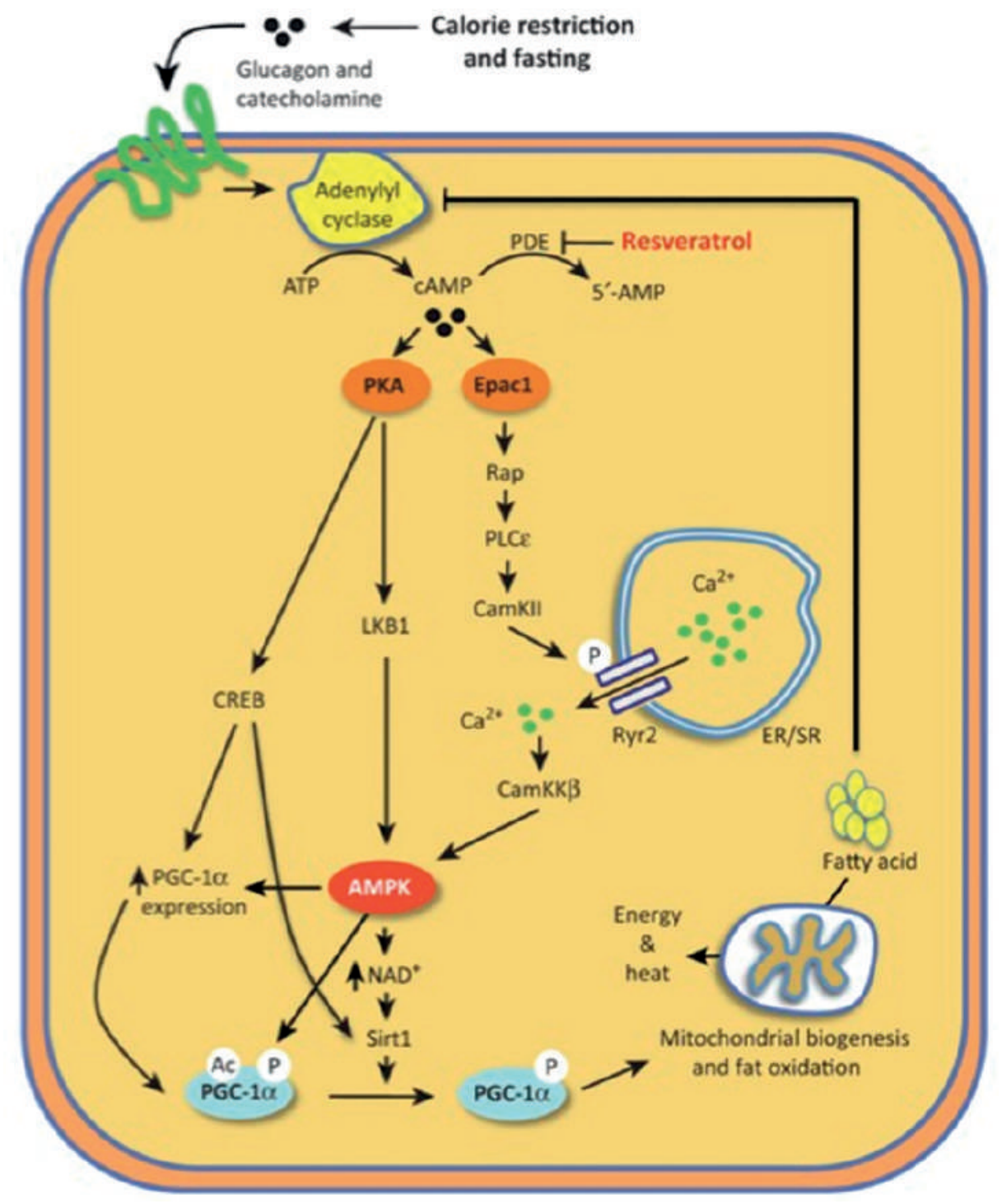

Figure 8. Resveratrol mimics calorie restriction by inhibiting cAMP phosphodiesterases (PDEs).(214) (Adapted with permission from Elsevier).

prolong human lifespan, such techniques have the potential to delay age-related physiological decline, and thus we anticipate that they will be useful in managing aging-related diseases and extending healthspan.(226)

\section{Conclusion}

Mitochondria plays a number of important roles in the cell, including oxidative phosphorylation, central carbon metabolism, and the biosynthesis of intermediates for cell development, but they are also involved in a number of other processes that influence cell function and fate. Mitochondrial malfunction is a hallmark of rare inherited mitochondrial illnesses and has also been linked to agerelated diseases, such as type 2 diabetes and Parkinson's disease, which affect the metabolic and neurological systems. Optimum mitochondria function can be maintained by a balanced mitochondrial biogenesis and mitophagy, mitochondrial dynamics and unfolded protein response. $\mathrm{CR}$ and $\mathrm{CR}$-mimetic agents can be one strategy to increase mitochondria biogenesis. To investigate these various aspects of mitochondrial function, we need more studies of phenotypic tests both in vitro and in vivo. Therefore, we hope to find an appealing therapeutic strategy for various of diseases by modulating mitochondrial function.

\section{Authors Contribution}

AM was involved in writing and revising the manuscript; NMD was involved in editing and revising the manuscript; AW was involved in proposing the frame of ideas of this writing, supervising, and proofreading. 


\section{References}

1. Liu X, Kim CN, Yang J, Jemmerson R, Wang X. Induction of apoptotic program in cell-free extracts: requirement for dATP and cytochrome c. Cell. 1996 Jul; 86: 147-57.

2. Frank S, Gaume B, Bergmann-Leitner ES, Leitner WW, Robert EG, Catez F, et al. The role of dynamin-related protein 1, a mediator of mitochondrial fission, in apoptosis. Dev Cell. 2001; 1: 515-25.

3. Khacho M, Clark A, Svoboda DS, Azzi J, MacLaurin JG, Meghaizel $\mathrm{C}$, et al. Mitochondrial dynamics impacts stem cell identity and fate decisions by regulating a nuclear transcriptional program. Cell Stem Cell. 2016; 19: 232-47.

4. Yasukawa K, Oshiumi H, Takeda M, Ishihara N, Yanagi Y, Seya T, et al. Mitofusin 2 inhibits mitochondrial antiviral signaling. Sci Signal. 2009 Aug; 2: ra47. doi: 10.1126/scisignal.2000287.

5. Picard M, Wallace DC, Burelle Y. The rise of mitochondria in medicine. Mitochondrion. 2016; 30: 105-16.

6. Zemirli N, Morel E, Molino D. Mitochondrial dynamics in basal and stressful conditions. IJMS. 2018; 19: 564. doi: 10.3390/ ijms 19020564 .

7. Suárez-Rivero JM, Villanueva-Paz M, De la Cruz-Ojeda P, De la Mata M, Cotán D, Oropesa-Ávila M, et al. Mitochondrial dynamics in mitochondrial diseases. diseases. 2017; 5: 1. doi: 10.3390/ diseases5010001.

8. Giacomello M, Pyakurel A, Glytsou C, Scorrano L. The cell biology of mitochondrial membrane dynamics. Nat Rev Mol Cell Biol. 2020; 21: 204-24.

9. Pagliarini DJ, Calvo SE, Chang B, Sheth SA, Vafai SB, Ong S-E, et al. A mitochondrial protein compendium elucidates complex I disease biology. Cell. 2008; 134: 112-23.

10. Eisner V, Picard M, Hajnóczky G. Mitochondrial dynamics in adaptive and maladaptive cellular stress responses. Nat Cell Biol. 2018; 20: 755-65.

11. Youle RJ, van der Bliek AM. Mitochondrial fission, fusion, and stress. Science. 2012; 337: 1062-5.

12. Kim TY, Wang D, Kim AK, Lau E, Lin AJ, Liem DA, et al. Metabolic labeling reveals proteome dynamics of mouse mitochondria. Mol Cell Proteomics. 2012; 11: 1586-94.

13. López-Otín C, Blasco MA, Partridge L, Serrano M, Kroemer G. The hallmarks of aging. Cell. 2013; 153: 1194-217.

14. Tseng AHH, Shieh S-S, Wang DL. SIRT3 deacetylates FOXO3 to protect mitochondria against oxidative damage. Free Radic Biol Med. 2013; 63: 222-34.

15. Davinelli S, De Stefani D, De Vivo I, Scapagnini G. Polyphenols as caloric restriction mimetics regulating mitochondrial biogenesis and mitophagy. Trends Endocrinol Metab. 2020; 31: 536-50.

16. Sugiura A, McLelland G, Fon EA, McBride HM. A new pathway for mitochondrial quality control: mitochondrial-derived vesicles. EMBO J. 2014; 33: 2142-56.

17. Neuspiel M, Schauss AC, Braschi E, Zunino R, Rippstein P, Rachubinski RA, et al. Cargo-selected transport from the mitochondria to peroxisomes is mediated by vesicular carriers. Curr Biol. 2008; 18: 102-8.

18. Soubannier V, McLelland G-L, Zunino R, Braschi E, Rippstein P, Fon EA, et al. A vesicular transport pathway shuttles cargo from mitochondria to lysosomes. Curr Biol. 2012; 22: 135-41.

19. Soubannier V, Rippstein P, Kaufman BA, Shoubridge EA, McBride HM. Reconstitution of mitochondria derived vesicle formation demonstrates selective enrichment of oxidized cargo. PLoS ONE. 2012; 7: e52830. doi: 10.1371/journal.pone.0052830.

20. Mcbride HM, Mohanty A. Emerging roles of mitochondria in the evolution, biogenesis, and function of peroxisomes. Front Physiol. 2013; 4: 268. doi: 10.3389/fphys.2013.00268.

21. Tatsuta $T$, Langer $T$. Quality control of mitochondria: protection against neurodegeneration and ageing. EMBO J. 2008; 27: 306-14.

22. Augustin S, Nolden M, Müller S, Hardt O, Arnold I, Langer T. Characterization of peptides released from mitochondria: evidence for constant proteolysis and peptide efflux. J Biol Chem. 2005; 280: 2691-9.

23. Casari G, De Fusco M, Ciarmatori S, Zeviani M, Mora M, Fernandez $\mathrm{P}$, et al. Spastic paraplegia and OXPHOS impairment caused by mutations in paraplegin, a nuclear-encoded mitochondrial metalloprotease. Cell. 1998 Jun; 93: 973-83.

24. Ahola S, Langer T, MacVicar T. Mitochondrial proteolysis and metabolic control. Cold Spring Harb Perspect Biol. 2019; 11: a033936. doi: 10.1101/cshperspect.a033936.

25. Quirós PM, Langer T, López-Otín C. New roles for mitochondrial proteases in health, ageing and disease. Nat Rev Mol Cell Biol. 2015; 16: 345-59.

26. Chan NC, Chan DC. Parkin uses the UPS to ship off dysfunctional mitochondria. Autophagy. 2011; 7: 771-2.

27. Ciechanover A. Early work on the ubiquitin proteasome system, an interview with Aaron Ciechanover. Interview by CDD. Cell Death Differ. 2005; 12: 1167-77.

28. Haas AL, Siepmann TJ. Pathways of ubiquitin conjugation. FASEB J. 1997; 11: 1257-68.

29. Hoeller D, Hecker CM, Dikic I. Ubiquitin and ubiquitin-like proteins in cancer pathogenesis. Nat Rev Cancer. 2006; 6: 776-88.

30. Ni HM, Williams JA, Ding WX. Mitochondrial dynamics and mitochondrial quality control. Redox Biol. 2015; 4: 6-13.

31. Baker MJ, Tatsuta T, Langer T. Quality control of mitochondrial proteostasis. Cold Spring Harb Perspect Biol. 2011; 3: a007559. doi: 10.1101/cshperspect.a007559.

32. Twig G, Elorza A, Molina AJA, Mohamed H, Wikstrom JD, Walzer G, et al. Fission and selective fusion govern mitochondrial segregation and elimination by autophagy. EMBO J. 2008; 27: 433-46.

33. Ding WX, Guo F, Ni HM, Bockus A, Manley S, Stolz DB, et al. Parkin and mitofusins reciprocally regulate mitophagy and mitochondrial spheroid formation. J Biol Chem. 2012; 287: 42379-88.

34. Pickles S, Vigié P, Youle RJ. Mitophagy and quality control mechanisms in mitochondrial maintenance. Curr Biol. 2018; 28: R170-85.

35. Campbell CT, Kolesar JE, Kaufman BA. Mitochondrial transcription factor A regulates mitochondrial transcription initiation, DNA packaging, and genome copy number. Biochim Biophys Acta Gene Regul Mech BBA - Gene Regul Mech. 2012; 1819: 921-9.

36. Wu Z, Puigserver P, Andersson U, Zhang C, Adelmant G, Mootha $\mathrm{V}$, et al. Mechanisms controlling mitochondrial biogenesis and respiration through the thermogenic coactivator PGC-1. Cell. 1999; 98: 115-24.

37. Lehman JJ, Barger PM, Kovacs A, Saffitz JE, Medeiros DM, Kelly DP. Peroxisome proliferator-activated receptor gamma coactivator-1 promotes cardiac mitochondrial biogenesis. J Clin Invest. 2000; 106: 847-56.

38. Baar K, Wende AR, Jones TE, Marison M, Nolte LA, Chen M, et al. Adaptations of skeletal muscle to exercise: rapid increase in the transcriptional coactivator PGC-1. FASEB J. 2002; 16: 1879-86.

39. Pilegaard H, Saltin B, Neufer PD. Exercise induces transient transcriptional activation of the PGC-1alpha gene in human skeletal muscle. J Physiol (Lond). 2003; 546: 851-8.

40. Arany Z, He H, Lin J, Hoyer K, Handschin C, Toka O, et al. Transcriptional coactivator PGC-1 $\alpha$ controls the energy state and contractile function of cardiac muscle. Cell Metab. 2005; 1: 25971. 
41. Cogliati S, Enriquez JA, Scorrano L. Mitochondrial cristae: where beauty meets functionality. Trends Biochem Sci. 2016; 41: 261-73.

42. Benard G, Bellance N, James D, Parrone P, Fernandez H, Letellier $\mathrm{T}$, et al. Mitochondrial bioenergetics and structural network organization. J Cell Sci. 2007; 120: 838-48.

43. Liesa M, Shirihai OS. Mitochondrial dynamics in the regulation of nutrient utilization and energy expenditure. Cell Metab. 2013; 17: 491-506.

44. Wai T, Langer T. Mitochondrial dynamics and metabolic regulation. Trends Endocrinol Metab. 2016; 27: 105-17.

45. Wesselink E, Koekkoek WAC, Grefte S, Witkamp RF, van Zanten ARH. Feeding mitochondria: Potential role of nutritional components to improve critical illness convalescence. Clin Nutr. 2019; 38: 982-95.

46. Tondera D, Grandemange S, Jourdain A, Karbowski M, Mattenberger $\mathrm{Y}$, Herzig S, et al. SLP-2 is required for stress-induced mitochondrial hyperfusion. EMBO J. 2009; 28: 1589-600.

47. Gomes LC, Di Benedetto G, Scorrano L. Essential amino acids and glutamine regulate induction of mitochondrial elongation during autophagy. Cell Cycle. 2011; 10: 2635-9.

48. Christie DA, Mitsopoulos P, Blagih J, Dunn SD, St-Pierre J, Jones $\mathrm{RG}$, et al. Stomatin-like protein 2 deficiency in $\mathrm{t}$ cells is associated with altered mitochondrial respiration and defective CD4 $+\mathrm{T}$ cell responses. J Immunol. 2012; 189: 4349-60.

49. Mitsopoulos P, Chang YH, Wai T, König T, Dunn SD, Langer T, et al. Stomatin-like protein 2 is required for in vivo mitochondrial respiratory chain supercomplex formation and optimal cell function. Mol Cell Biol. 2015; 35: 1838-47.

50. Qiu H, Schlegel V. Impact of nutrient overload on metabolic homeostasis. Nutr Rev. 2018; 76: 693-707.

51. Lisowski P, Kannan P, Mlody B, Prigione A. Mitochondria and the dynamic control of stem cell homeostasis. EMBO Rep. 2018; 19(5): e45432. doi: 10.15252/embr.201745432.

52. Mishra $\mathrm{P}$, Chan DC. Metabolic regulation of mitochondrial dynamics. J Cell Biol. 2016; 212: 379-87.

53. Sebastián D, Zorzano A. Mitochondrial dynamics and metabolic homeostasis. Curr Opin Physiol. 2018; 3: 34-40.

54. Bahat A, Gross A. Mitochondrial plasticity in cell fate regulation. J Biol Chem. 2019; 294: 13852-63.

55. Chen H, Detmer SA, Ewald AJ, Griffin EE, Fraser SE, Chan DC. Mitofusins Mfn1 and Mfn2 coordinately regulate mitochondrial fusion and are essential for embryonic development. J Cell Biol. 2003; 160: 189-200.

56. Anand R, Wai T, Baker MJ, Kladt N, Schauss AC, Rugarli E, et al. The i-AAA protease YME1L and OMA1 cleave OPA1 to balance mitochondrial fusion and fission. J Cell Biol. 2014; 204: 919-29.

57. Ishihara N, Fujita Y, Oka T, Mihara K. Regulation of mitochondrial morphology through proteolytic cleavage of OPA1. EMBO J. 2006; 25: 2966-77.

58. Baker MJ, Lampe PA, Stojanovski D, Korwitz A, Anand R, Tatsuta $\mathrm{T}$, et al. Stress-induced OMA1 activation and autocatalytic turnover regulate OPA1-dependent mitochondrial dynamics. EMBO J. 2014; 33: 578-93.

59. Head B, Griparic L, Amiri M, Gandre-Babbe S, van der Bliek AM. Inducible proteolytic inactivation of OPA1 mediated by the OMA1 protease in mammalian cells. J Cell Biol. 2009; 187: 959-66.

60. Duvezin-Caubet S, Jagasia R, Wagener J, Hofmann S, Trifunovic A, Hansson A, et al. Proteolytic processing of OPA1 links mitochondrial dysfunction to alterations in mitochondrial morphology. J Biol Chem. 2006; 281: 37972-9.

61. Makino A, Suarez J, Gawlowski T, Han W, Wang H, Scott BT, et al. Regulation of mitochondrial morphology and function by O-GlcNAcylation in neonatal cardiac myocytes. Am J Physiol
Regul Integr Comp Physiol. 2011; 300: R1296-302.

62. Samant SA, Zhang HJ, Hong Z, Pillai VB, Sundaresan NR, Wolfgeher $\mathrm{D}$, et al. SIRT3 deacetylates and activates OPA1 to regulate mitochondrial dynamics during stress. Mol Cell Biol. 2014; 34: 807-19.

63. Smirnova E, Griparic L, Shurland D-L, van der Bliek AM. Dynaminrelated protein Drp1 is required for mitochondrial division in mammalian cells. MBoC. 2001; 12: 2245-56.

64. Labbé K, Murley A, Nunnari J. Determinants and functions of mitochondrial behavior. Annu Rev Cell Dev Biol. 2014; 30: 35791.

65. West AP, Shadel GS, Ghosh S. Mitochondria in innate immune responses. Nat Rev Immunol. 2011; 11: 389-402.

66. Zhou R, Yazdi AS, Menu P, Tschopp J. A role for mitochondria in NLRP3 inflammasome activation. Nature. 2011; 469: 221-5.

67. Iyer SS, He Q, Janczy JR, Elliott EI, Zhong Z, Olivier AK, et al. Mitochondrial cardiolipin is required for Nlrp3 inflammasome activation. Immunity. 2013; 39: 311-23.

68. Park S, Won JH, Hwang I, Hong S, Lee HK, Yu JW. Defective mitochondrial fission augments NLRP3 inflammasome activation. Sci Rep. 2015; 5: 15489. doi: 10.1038/srep15489.

69. Wong YC, Ysselstein D, Krainc D. Mitochondria-lysosome contacts regulate mitochondrial fission via RAB7 GTP hydrolysis. Nature. 2018; 554: 382-6.

70. Schmitt K, Grimm A, Dallmann R, Oettinghaus B, Restelli LM, Witzig M, et al. Circadian control of DRP1 activity regulates mitochondrial dynamics and bioenergetics. Cell Metab. 2018; 27: 657-666.e5.

71. Tilokani L, Nagashima S, Paupe V, Prudent J. Mitochondrial dynamics: overview of molecular mechanisms. Essays Biochem. 2018; 62: 341-60.

72. Tait SWG, Green DR. Mitochondria and cell signalling. J Cell Sci. 2012; 125: 807-15.

73. Settembre C, Fraldi A, Medina DL, Ballabio A. Signals from the lysosome: a control centre for cellular clearance and energy metabolism. Nat Rev Mol Cell Biol. 2013; 14: 283-96.

74. Ballabio A, Bonifacino JS. Lysosomes as dynamic regulators of cell and organismal homeostasis. Nat Rev Mol Cell Biol. 2020; 21: 101-18.

75. Herzig S, Shaw RJ.AMPK: guardian of metabolism and mitochondrial homeostasis. Nat Rev Mol Cell Biol. 2018; 19: 121-35.

76. Scarpulla RC, Vega RB, Kelly DP. Transcriptional integration of mitochondrial biogenesis. Trends Endocrinol Metab. 2012; 23: 459-66.

77. Quirós PM, Mottis A, Auwerx J. Mitonuclear communication in homeostasis and stress. Nat Rev Mol Cell Biol. 2016; 17: 213-26.

78. Cantó C, Gerhart-Hines Z, Feige JN, Lagouge M, Noriega L, Milne $\mathrm{JC}$, et al. AMPK regulates energy expenditure by modulating NAD+ metabolism and SIRT1 activity. Nature. 2009; 458: 1056-60.

79. Cantó C, Jiang LQ, Deshmukh AS, Mataki C, Coste A, Lagouge M, et al. Interdependence of AMPK and SIRT1 for metabolic adaptation to fasting and exercise in skeletal muscle. Cell Metab. 2010; 11: 213-9.

80. Garcia-Roves PM, Osler ME, Holmström MH, Zierath JR. Gainof-function R225Q mutation in AMP-activated protein kinase $\gamma 3$ subunit increases mitochondrial biogenesis in glycolytic skeletal muscle. J Biol Chem. 2008; 283: 35724-34.

81. Wu H, Kanatous SB, Thurmond FA, Gallardo T, Isotani E, BasselDuby R, et al. Regulation of mitochondrial biogenesis in skeletal muscle by CaMK. Science. 2002; 296: 349-52.

82. Woods A, Dickerson K, Heath R, Hong SP, Momcilovic M, Johnstone $\mathrm{SR}$, et al. $\mathrm{Ca} 2+/$ calmodulin-dependent protein kinase kinase-beta acts upstream of AMP-activated protein kinase in mammalian cells. 
Cell Metab. 2005; 2: 21-33.

83. Jazwinski SM. The retrograde response: When mitochondrial quality control is not enough. Biochim Biophys Acta Mol Cell Res. 2013; 1833: 400-9.

84. Andreux PA, Houtkooper RH, Auwerx J. Pharmacological approaches to restore mitochondrial function. Nat Rev Drug Discov. 2013; 12 : 465-83.

85. Friedman JR, Nunnari J. Mitochondrial form and function. Nature. 2014; 505: 335-43.

86. Crozet P, Margalha L, Confraria A, Rodrigues A, Martinho C, Adamo $\mathrm{M}$, et al. Mechanisms of regulation of SNF1/AMPK/SnRK1 protein kinases. Front Plant Sci. 2014; 5: 190. doi: 10.3389/ fpls.2014.00190.

87. Inoki K, Zhu T, Guan K-L. TSC2 mediates cellular energy response to control cell growth and survival. Cell. 2003; 115: 577-90.

88. Gwinn DM, Shackelford DB, Egan DF, Mihaylova MM, Mery A, Vasquez DS, et al. AMPK phosphorylation of raptor mediates a metabolic checkpoint. Mol Cell. 2008; 30: 214-26.

89. Carling D, Zammit VA, Hardie DG. A common bicyclic protein kinase cascade inactivates the regulatory enzymes of fatty acid and cholesterol biosynthesis. FEBS Lett. 1987; 223: 217-22.

90. Munday MR, Campbell DG, Carling D, Hardie DG. Identification by amino acid sequencing of three major regulatory phosphorylation sites on rat acetyl-CoA carboxylase. Eur J Biochem. 1988; 175: 331-8.

91. Marsin AS, Bertrand L, Rider MH, Deprez J, Beauloye C, Vincent MF, et al. Phosphorylation and activation of heart PFK-2 by AMPK has a role in the stimulation of glycolysis during ischaemia. Curr Biol. 2000; 10: 1247-55.

92. Bando H. Phosphorylation of the 6-phosphofructo-2-kinase/fructose 2,6-bisphosphatase/PFKFB3 family of glycolytic regulators in human cancer. Clin Cancer Res. 2005; 11: 5784-92.

93. Jäger S, Handschin C, St-Pierre J, Spiegelman BM. AMP-activated protein kinase (AMPK) action in skeletal muscle via direct phosphorylation of PGC-1alpha. Proc Natl Acad Sci USA. 2007; 104: 12017-22.

94. Egan DF, Shackelford DB, Mihaylova MM, Gelino S, Kohnz RA, Mair W, et al. Phosphorylation of ULK1 (hATG1) by AMPactivated protein kinase connects energy sensing to mitophagy. Science. 2011; 331: 456-61.

95. Berridge MJ, Bootman MD, Lipp P. Calcium--a life and death signal. Nature. 1998; 395: 645-8.

96. Kamer KJ, Mootha VK. The molecular era of the mitochondrial calcium uniporter. Nat Rev Mol Cell Biol. 2015; 16: 545-53.

97. Shadel GS, Horvath TL. Mitochondrial ROS signaling in organismal homeostasis. Cell. 2015; 163: 560-9.

98. Dinkova-Kostova AT, Abramov AY. The emerging role of Nrf2 in mitochondrial function. Free Radic Biol Med. 2015; 88: 179-88.

99. Wild AC, Moinova HR, Mulcahy RT. Regulation of gammaglutamylcysteine synthetase subunit gene expression by the transcription factor Nrf2. J Biol Chem. 1999; 274: 33627-36.

100. Sasaki H, Sato H, Kuriyama-Matsumura K, Sato K, Maebara K, Wang $\mathrm{H}$, et al. Electrophile response element-mediated induction of the cystine/glutamate exchange transporter gene expression. J Biol Chem. 2002; 277: 44765-71.

101. Thimmulappa RK, Mai KH, Srisuma S, Kensler TW, Yamamoto M, Biswal S. Identification of Nrf2-regulated genes induced by the chemopreventive agent sulforaphane by oligonucleotide microarray. Cancer Res. 2002; 62: 5196-203.

102. Ushida Y, Talalay P. sulforaphane accelerates acetaldehyde metabolism by inducing aldehyde dehydrogenases: relevance to ethanol intolerance. Alcohol Alcohol. 2013; 48: 526-34.
103. Holmström KM, Baird L, Zhang Y, Hargreaves I, Chalasani A, Land JM, et al. Nrf2 impacts cellular bioenergetics by controlling substrate availability for mitochondrial respiration. Biol Open. 2013; 2: 761-70.

104. Greco T, Fiskum G. Brain mitochondria from rats treated with sulforaphane are resistant to redox-regulated permeability transition. J Bioenerg Biomembr. 2010; 42: 491-7.

105. Picard M, McEwen BS, Epel ES, Sandi C. An energetic view of stress: focus on mitochondria. Front Neuroendocrinol. 2018; 49: $72-85$.

106. Lemasters JJ. Rusty notions of cell injury. J Hepatol. 2004; 40: 696-8.

107. Rizzuto R, De Stefani D, Raffaello A, Mammucari C. Mitochondria as sensors and regulators of calcium signalling. Nat Rev Mol Cell Biol. 2012; 13: 566-78.

108. Bagur R, Hajnóczky G. Intracellular Ca2+ sensing: its role in calcium homeostasis and signaling. Mol Cell. 2017; 66: 780-8.

109. Holmström KM, Finkel T. Cellular mechanisms and physiological consequences of redox-dependent signalling. Nat Rev Mol Cell Biol. 2014; 15: 411-21.

110. Liu X, Hajnóczky G. Altered fusion dynamics underlie unique morphological changes in mitochondria during hypoxiareoxygenation stress. Cell Death Differ. 2011; 18: 1561-72.

111. Zemirli N, Pourcelot M, Ambroise G, Hatchi E, Vazquez A, Arnoult D. Mitochondrial hyperfusion promotes NF- $\mathrm{kB}$ activation via the mitochondrial E3 ligase MULAN. FEBS J. 2014; 281: 3095-112.

112. Kikis EA, Gidalevitz T, Morimoto RI. Protein homeostasis in models of aging and age-related conformational disease. Adv Exp Med Biol. 2010; 694: 138-59.

113. Vabulas RM, Raychaudhuri S, Hayer-Hartl M, Hartl FU. Protein folding in the cytoplasm and the heat shock response. Cold Spring Harb Perspect Biol. 2010; 2: a004390. doi: 10.1101/cshperspect. a004390.

114. Walter P, Ron D. The unfolded protein response: from stress pathway to homeostatic regulation. Science. 2011; 334: 1081-6.

115. Haynes CM, Ron D. The mitochondrial UPR - protecting organelle protein homeostasis. J Cell Sci. 2010; 123: 3849-55.

116. Jovaisaite V, Mouchiroud L, Auwerx J. The mitochondrial unfolded protein response, a conserved stress response pathway with implications in health and disease. J Exp Biol. 2014; 217: 137-43.

117. Harding HP, Novoa I, Zhang Y, Zeng H, Wek R, Schapira M, et al. Regulated translation initiation controls stress-induced gene expression in mammalian cells. Mol Cell. 2000; 6: 1099-108.

118. Harding HP, Zhang Y, Zeng H, Novoa I, Lu PD, Calfon M, et al. An integrated stress response regulates amino acid metabolism and resistance to oxidative stress. Mol Cell. 2003; 11: 619-33.

119. Donnelly N, Gorman AM, Gupta S, Samali A. The eIF2 $\alpha$ kinases: their structures and functions. Cell Mol Life Sci. 2013; 70: 3493511.

120. Palam LR, Baird TD, Wek RC. Phosphorylation of eIF2 facilitates ribosomal bypass of an inhibitory upstream ORF to enhance CHOP translation. J Biol Chem. 2011; 286: 10939-49.

121. Durieux J, Wolff S, Dillin A. The cell-non-autonomous nature of electron transport chain-mediated longevity. Cell. 2011; 144: 7991.

122. Rathmell JC, Thompson CB. Pathways of apoptosis in lymphocyte development, homeostasis, and disease. Cell. 2002; 109: S97-107.

123. Sedger LM, Katewa A, Pettersen AK, Osvath SR, Farrell GC, Stewart GJ, et al. Extreme lymphoproliferative disease and fatal autoimmune thrombocytopenia in FasL and TRAIL doubledeficient mice. Blood. 2010; 115: 3258-68.

124. Su JH, Deng G, Cotman CW. Bax protein expression is increased in Alzheimer's brain: correlations with DNA damage, Bcl-2 
expression, and brain pathology. J Neuropathol Exp Neurol. 1997; 56: 86-93.

125. Lu T, Aron L, Zullo J, Pan Y, Kim H, Chen Y, et al. REST and stress resistance in ageing and Alzheimer's disease. Nature. 2014; 507: 448-54.

126. Honarpour N, Gilbert SL, Lahn BT, Wang X, Herz J. Apaf-1 deficiency and neural tube closure defects are found in fog mice. PNAS. 2001; 98: 9683-7.

127. Ke FFS, Vanyai HK, Cowan AD, Delbridge ARD, Whitehead L, Grabow S, et al. Embryogenesis and adult life in the absence of intrinsic apoptosis effectors BAX, BAK, and BOK. Cell. 2018; 173: 1217-1230.e17.

128. Knudson CM, Tung KSK, Tourtellotte WG, Brown GAJ, Korsmeyer SJ. Bax-deficient mice with lymphoid hyperplasia and male germ cell death. Science. 1995; 270: 96-9.

129. Eischen CM, Roussel MF, Korsmeyer SJ, Cleveland JL. Bax loss impairs Myc-induced apoptosis and circumvents the selection of p53 mutations during Myc-mediated lymphomagenesis. Mol Cell Biol. 2001; 21: 7653-62.

130. Luke JJ, van de Wetering CI, Knudson CM. Lymphoma development in Bax transgenic mice is inhibited by Bcl-2 and associated with chromosomal instability. Cell Death Differ. 2003; 10: 740-8.

131. Los M, Van de Craen M, Penning LC, Schenk H, Westendorp M, Baeuerle PA, et al. Requirement of an ICE/CED-3 protease for Fas/ APO-1-mediated apoptosis. Nature. 1995; 375: 81-3.

132. Galluzzi L, Vitale I, Aaronson SA, Abrams JM, Adam D, Agostinis P, et al. Molecular mechanisms of cell death: recommendations of the Nomenclature Committee on Cell Death 2018. Cell Death Differ. 2018; 25: 486-541.

133. Singh R, Letai A, Sarosiek K. Regulation of apoptosis in health and disease: the balancing act of BCL-2 family proteins. Nat Rev Mol Cell Biol. 2019; 20: 175-93.

134. Bock FJ, Tait SWG. Mitochondria as multifaceted regulators of cell death. Nat Rev Mol Cell Biol. 2020; 21: 85-100.

135. Ernster L, Schatz G. Mitochondria: a historical review. J Cell Biol. 1981; 91: 227s-55s.

136. Riera CE, Dillin A. Tipping the metabolic scales towards increased longevity in mammals. Nat Cell Biol. 2015; 17: 196-203.

137. Nargund AM, Pellegrino MW, Fiorese CJ, Baker BM, Haynes CM. Mitochondrial import efficiency of ATFS-1 regulates mitochondrial UPR activation. Science. 2012; 337: 587-90.

138. Nagaraj R, Sharpley MS, Chi F, Braas D, Zhou Y, Kim R, et al. Nuclear localization of mitochondrial TCA cycle enzymes as a critical step in mammalian zygotic genome activation. Cell. 2017; 168: 210-223.e11.

139. Kourtis N, Tavernarakis N. Cellular stress response pathways and ageing: intricate molecular relationships. EMBO J. 2011; 30: 252031.

140. Haigis MC, Yankner BA. The aging stress response. Mol Cell. 2010; 40: 333-44.

141. Holzenberger M, Dupont J, Ducos B, Leneuve P, Géloën A, Even PC, et al. IGF-1 receptor regulates lifespan and resistance to oxidative stress in mice. Nature. 2003; 421: 182-7.

142. Gems D, Partridge L. Stress-response hormesis and aging: "that which does not kill us makes us stronger." Cell Metab. 2008; 7: $200-3$.

143. Meiliana A, Wijaya A. Hormesis in health and disease: molecular mechanisms. Indones Biomed J. 2020; 12: 288-303.

144. Koppen M, Langer T. Protein degradation within mitochondria: versatile activities of AAA proteases and other peptidases. Crit Rev Biochem Mol Biol. 2007; 42: 221-42.

145. Anand R, Langer T, Baker MJ. Proteolytic control of mitochondrial function and morphogenesis. Biochim Biophys Acta. 2013; 1833: 195-204.

146. Rugarli EI, Langer T. Mitochondrial quality control: a matter of life and death for neurons. EMBO J. 2012; 31: 1336-49.

147. Baker BM, Haynes CM. Mitochondrial protein quality control during biogenesis and aging. Trends Biochem Sci. 2011; 36: 254-61.

148. Lionaki E, Tavernarakis N. Oxidative stress and mitochondrial protein quality control in aging. J Proteomics. 2013; 92: 181-94.

149. Salama R, Sadaie M, Hoare M, Narita M. Cellular senescence and its effector programs. Genes Dev. 2014; 28: 99-114.

150. Kuilman T, Michaloglou C, Mooi WJ, Peeper DS. The essence of senescence. Genes Dev. 2010; 24: 2463-79.

151. Herranz N, Gil J. Mitochondria and senescence: new actors for an old play. EMBO J. 2016; 35: 701-2.

152. Vasileiou P, Evangelou K, Vlasis K, Fildisis G, Panayiotidis M, Chronopoulos E, et al. Mitochondrial homeostasis and cellular senescence. Cells. 2019; 8: 686. doi: 10.3390/cells8070686.

153. Chapman J, Fielder E, Passos JF. Mitochondrial dysfunction and cell senescence: deciphering a complex relationship. FEBS Lett. 2019; 593: 1566-79.

154. Gorgoulis VG, Pefani D-E, Pateras IS, Trougakos IP. Integrating the DNA damage and protein stress responses during cancer development and treatment. J Pathol. 2018; 246: 12-40.

155. Park SY, Choi B, Cheon H, Pak YK, Kulawiec M, Singh KK, et al. Cellular aging of mitochondrial DNA-depleted cells. Biochem Biophys Res Commun. 2004; 325: 1399-405.

156. Kelly DP, Scarpulla R. Transcriptional regulatory circuits controlling mitochondrial biogenesis and function. Genes Dev. 2004; 18 : $357-$ 68.

157. White FA, Bunn CL. Restriction enzyme analysis of mitochondrial DNA in aging human cells. Mech Ageing Dev. 1985; 30: 153-68.

158. Garesse R, Vallejo CG. Animal mitochondrial biogenesis and function: a regulatory cross-talk between two genomes. Gene. 2001; 263: 1-16.

159. Andersson SGE, Karlberg O, Canbäck B, Kurland CG. On the origin of mitochondria: a genomics perspective. Philos Trans R Soc Lond B Biol Sci. 2003; 358: 165-77.

160. Taanman JW. The mitochondrial genome: structure, transcription, translation and replication. Biochim Biophys Acta Bioenerg. 1999; 1410: 103-23.

161. Gerhold JM, Cansiz-Arda Ş, Lõhmus M, Engberg O, Reyes A, van Rennes $\mathrm{H}$, et al. Human mitochondrial DNA-protein complexes attach to a cholesterol-rich membrane structure. Sci Rep. 2015; 5: 15292. doi: 10.1038/srep15292.

162. Kasashima K, Endo H. Interaction of human mitochondrial transcription factor $\mathrm{A}$ in mitochondria: its involvement in the dynamics of mitochondrial DNA nucleoids. Genes Cells. 2015; 20: 1017-27.

163. van de Ven RAH, Santos D, Haigis MC. Mitochondrial sirtuins and molecular mechanisms of aging. Trends Mol Med. 2017; 23: 32031.

164. Li X, Egervari G, Wang Y, Berger SL, Lu Z. Regulation of chromatin and gene expression by metabolic enzymes and metabolites. Nat Rev Mol Cell Biol. 2018; 19: 563-78.

165. Cheng X. Structural and functional coordination of DNA and histone methylation. Cold Spring Harb Perspect Biol. 2014; 6: a018747. doi: 10.1101/cshperspect.a018747.

166. Berger SL. The complex language of chromatin regulation during transcription. Nature. 2007; 447: 407-12.

167. Schvartzman JM, Thompson CB, Finley LWS. Metabolic regulation of chromatin modifications and gene expression. Int J Cell Biol. 2018; 217: 2247-59. 
168. Chantranupong L, Wolfson RL, Sabatini DM. Nutrient-sensing mechanisms across evolution. Cell. 2015; 161: 67-83.

169. Shyh-Chang N, Daley GQ, Cantley LC. Stem cell metabolism in tissue development and aging. Development. 2013; 140: 2535-47.

170. Shyh-Chang N, Ng HH. The metabolic programming of stem cells. Genes Dev. 2017; 31: 336-46.

171. Riester M, Xu Q, Moreira A, Zheng J, Michor F, Downey RJ. The Warburg effect: persistence of stem-cell metabolism in cancers as a failure of differentiation. Ann Oncol. 2018; 29: 264-70.

172. Ma T, Li J, Xu Y, Yu C, Xu T, Wang H, et al. Atg5-independent autophagy regulates mitochondrial clearance and is essential for iPSC reprogramming. Nat Cell Biol. 2015; 17: 1379-87.

173. Bricker DK, Taylor EB, Schell JC, Orsak T, Boutron A, Chen YC, et al. A mitochondrial pyruvate carrier required for pyruvate uptake in yeast, Drosophila, and humans. Science. 2012; 337: 96-100.

174. Herzig S, Raemy E, Montessuit S, Veuthey JL, Zamboni N, Westermann $\mathrm{B}$, et al. Identification and functional expression of the mitochondrial pyruvate carrier. Science. 2012; 337: 93-6.

175. Schell JC, Olson KA, Jiang L, Hawkins AJ, Van Vranken JG, Xie J, et $a l$. A role for the mitochondrial pyruvate carrier as a repressor of the Warburg effect and colon cancer cell growth. Mol Cell. 2014; 56: 400-13.

176. Schell JC, Wisidagama DR, Bensard C, Zhao H, Wei P, Tanner J, et al. Control of intestinal stem cell function and proliferation by mitochondrial pyruvate metabolism. Nat Cell Biol. 2017; 19: 102736.

177. Wang J, Alexander P, Wu L, Hammer R, Cleaver O, McKnight SL. Dependence of mouse embryonic stem cells on threonine catabolism. Science. 2009; 325: 435-9.

178. TeSlaa T, Chaikovsky AC, Lipchina I, Escobar SL, Hochedlinger K, Huang $\mathrm{J}$, et al. $\alpha$-ketoglutarate accelerates the initial differentiation of primed human pluripotent stem cells. Cell Metab. 2016; 24: 48593.

179. Moussaieff A, Rouleau M, Kitsberg D, Cohen M, Levy G, Barasch $\mathrm{D}$, et al. Glycolysis-mediated changes in acetyl-CoA and histone acetylation control the early differentiation of embryonic stem cells. Cell Metab. 2015; 21: 392-402.

180. Sivanand S, Viney I, Wellen KE. Spatiotemporal control of acetylCoA metabolism in chromatin regulation. Trends Biochem Sci. 2018; 43: 61-74.

181. Wellen KE, Hatzivassiliou G, Sachdeva UM, Bui TV, Cross JR, Thompson CB. ATP-citrate lyase links cellular metabolism to histone acetylation. Science. 2009; 324: 1076-80.

182. Nunnari J, Suomalainen A. Mitochondria: in sickness and in health. Cell. 2012; 148: 1145-59.

183. Smith RAJ, Hartley RC, Cochemé HM, Murphy MP. Mitochondrial pharmacology. Trends Pharmacol Sci. 2012; 33: 341-52.

184. Whitaker RM, Corum D, Beeson CC, Schnellmann RG. Mitochondrial biogenesis as a pharmacological target: a new approach to acute and chronic diseases. Annu Rev Pharmacol Toxicol. 2016; 56: 229-49.

185. Murphy MP, Hartley RC. Mitochondria as a therapeutic target for common pathologies. Nat Rev Drug Discov. 2018; 17: 865-86.

186. Koopman WJH, Distelmaier F, Esseling JJ, Smeitink JAM, Willems PHGM. Computer-assisted live cell analysis of mitochondrial membrane potential, morphology and calcium handling. Methods. 2008; 46: 304-11.

187. Heusch G, Gersh BJ. The pathophysiology of acute myocardial infarction and strategies of protection beyond reperfusion: a continual challenge. Eur Heart J. 2017; 38: 774-84.

188. Waldman M, Cohen K, Yadin D, Nudelman V, Gorfil D, LaniadoSchwartzman M, et al. Regulation of diabetic cardiomyopathy by caloric restriction is mediated by intracellular signaling pathways involving 'SIRT1 and PGC-1 $\alpha$. ' Cardiovasc Diabetol. 2018; 17: 111. doi: 10.1186/s12933-018-0754-4.

189. Kim DH, Park MH, Ha S, Bang EJ, Lee Y, Lee AK, et al. Antiinflammatory action of $\beta$-hydroxybutyrate via modulation of PGC$1 \alpha$ and FoxO1, mimicking calorie restriction. Aging. 2019; 11: 1283-304.

190. Alcocer-Gómez E, Garrido-Maraver J, Bullón P, Marín-Aguilar F, Cotán D, Carrión AM, et al. Metformin and caloric restriction induce an AMPK-dependent restoration of mitochondrial dysfunction in fibroblasts from Fibromyalgia patients. Biochim Biophys Acta Mol Basis Dis. 2015; 1852: 1257-67.

191. Silvestre MFP, Viollet B, Caton PW, Leclerc J, Sakakibara I, Foretz $\mathrm{M}$, et al. The AMPK-SIRT signaling network regulates glucose tolerance under calorie restriction conditions. Life Sciences. 2014; 100: 55-60.

192. Kobayashi M, Takeda K, Narita T, Nagai K, Okita N, Sudo Y, et al. Mitochondrial intermediate peptidase is a novel regulator of sirtuin-3 activation by caloric restriction. FEBS Letters. 2017; 591: 4067-73.

193. López-Lluch G, Hunt N, Jones B, Zhu M, Jamieson H, Hilmer S, et al. Calorie restriction induces mitochondrial biogenesis and bioenergetic efficiency. Proc Natl Acad Sci USA. 2006; 103: 176873.

194. Hancock CR, Han D-H, Higashida K, Kim SH, Holloszy JO. Does calorie restriction induce mitochondrial biogenesis? A reevaluation. FASEB J. 2011; 25: 785-91.

195. Lanza IR, Zabielski P, Klaus KA, Morse DM, Heppelmann CJ, Bergen $\mathrm{HR}$, et al. Chronic caloric restriction preserves mitochondrial function in senescence without increasing mitochondrial biogenesis. Cell Metab. 2012; 16: 777-88.

196. Houtkooper RH, Pirinen E, Auwerx J. Sirtuins as regulators of metabolism and healthspan. Nat Rev Mol Cell Biol. 2012; 13: 22538.

197. Toiber D, Sebastian C, Mostoslavsky R. Characterization of nuclear sirtuins: molecular mechanisms and physiological relevance. Handb Exp Pharmacol. 2011; 206: 189-224.

198. Fernandez-Marcos PJ, Auwerx J. Regulation of PGC-1 $\alpha$, a nodal regulator of mitochondrial biogenesis. Am J Clin Nutr. 2011; 93: 884S-90

199. Nakagawa T, Guarente L. SnapShot: sirtuins, NAD, and aging. Cell Metab. 2014; 20: 192-192.e1

200. Luo J, Nikolaev AY, Imai S, Chen D, Su F, Shiloh A, et al. Negative control of p53 by Sir2alpha promotes cell survival under stress. Cell. 2001; 107: 137-48.

201. Vaziri H, Dessain SK, Eaton EN, Imai S-I, Frye RA, Pandita TK, et al. hSIR2SIRT1 functions as an NAD-dependent p53 deacetylase. Cell. 2001; 107: 149-59.

202. Yeung F, Hoberg JE, Ramsey CS, Keller MD, Jones DR, Frye RA, et al. Modulation of NF-kappaB-dependent transcription and cell survival by the SIRT1 deacetylase. EMBO J. 2004; 23: 2369-80.

203. Rodgers JT, Lerin C, Haas W, Gygi SP, Spiegelman BM, Puigserver P. Nutrient control of glucose homeostasis through a complex of PGC-1alpha and SIRT1. Nature. 2005; 434: 113-8.

204. Walker AK, Yang F, Jiang K, Ji JY, Watts JL, Purushotham A, et al. Conserved role of SIRT1 orthologs in fasting-dependent inhibition of the lipid/cholesterol regulator SREBP. Genes Dev. 2010; 24: 1403-17.

205. Tanner KG, Landry J, Sternglanz R, Denu JM. Silent information regulator 2 family of NAD- dependent histone/protein deacetylases generates a unique product, 1-O-acetyl-ADP-ribose. Proc Natl Acad Sci USA. 2000; 97: 14178-82. 
206. Bitterman KJ, Anderson RM, Cohen HY, Latorre-Esteves M, Sinclair DA. Inhibition of silencing and accelerated aging by nicotinamide, a putative negative regulator of yeast sir2 and human SIRT1. J Biol Chem. 2002; 277: 45099-107.

207. Landry J, Slama JT, Sternglanz R. Role of NAD(+) in the deacetylase activity of the SIR2-like proteins. Biochem Biophys Res Commun. 2000; 278: 685-90.

208. Howitz KT, Bitterman KJ, Cohen HY, Lamming DW, Lavu S, Wood JG, et al. Small molecule activators of sirtuins extend Saccharomyces cerevisiae lifespan. Nature. 2003; 425: 191-6.

209. Milne JC, Lambert PD, Schenk S, Carney DP, Smith JJ, Gagne DJ, et al. Small molecule activators of SIRT1 as therapeutics for the treatment of type 2 diabetes. Nature. 2007; 450: 712-6.

210. Dai H, Kustigian L, Carney D, Case A, Considine T, Hubbard BP, et al. SIRT1 activation by small molecules: kinetic and biophysical evidence for direct interaction of enzyme and activator. J Biol Chem. 2010; 285: 32695-703.

211. Hubbard BP, Sinclair DA. Small molecule SIRT1 activators for the treatment of aging and age-related diseases. Trends Pharmacol Sci. 2014; 35: 146-54.

212. Bonkowski MS, Sinclair DA. Slowing ageing by design: the rise of NAD+ and sirtuin-activating compounds. Nat Rev Mol Cell Biol. 2016; 17: 679-90.

213. Madeo F, Carmona-Gutierrez D, Hofer SJ, Kroemer G. Caloric restriction mimetics against age-associated disease: targets, mechanisms, and therapeutic potential. Cell Metab. 2019; 29: 592610.

214. Chung JH, Manganiello V, Dyck JRB. Resveratrol as a calorie restriction mimetic: therapeutic implications. Trends Cell Biol. 2012; 22: 546-54.

215. Cao W, Dou Y, Li A. Resveratrol boosts cognitive function by targeting SIRT1. Neurochem Res. 2018; 43: 1705-13.

216. Baur JA, Pearson KJ, Price NL, Jamieson HA, Lerin C, Kalra A, et al.
Resveratrol improves health and survival of mice on a high-calorie diet. Nature. 2006; 444: 337-42.

217. Kim SK, Joe Y, Zheng M, Kim HJ, Yu JK, Cho GJ, et al. Resveratrol induces hepatic mitochondrial biogenesis through the sequential activation of nitric oxide and carbon monoxide production. Antioxid Redox Signal. 2013; 20: 2589-605.

218. Cao K, Zheng A, Xu J, Li H, Liu J, Peng Y, et al. AMPK activation prevents prenatal stress-induced cognitive impairment: Modulation of mitochondrial content and oxidative stress. Free Radic Biol Med. 2014; 75: 156-66.

219. Vargas-Ortiz K, Pérez-Vázquez V, Macías-Cervantes MH. Exercise and sirtuins: a way to mitochondrial health in skeletal muscle. Int $\mathrm{J}$ Mol Sci. 2019; 20: 2717. doi: 10.3390/ijms20112717.

220. Verdin E. NAD+ in aging, metabolism, and neurodegeneration. Science. 2015; 350: 1208-13.

221. Imai S, Armstrong CM, Kaeberlein M, Guarente L. Transcriptional silencing and longevity protein Sir2 is an NAD-dependent histone deacetylase. Nature. 2000; 403: 795-800.

222. Chini EN. Of mice and men: NAD+ boosting with niacin provides hope for mitochondrial myopathy patients. Cell Metab. 2020; 31: 1041-3.

223. Cantó C, Houtkooper RH, Pirinen E, Youn DY, Oosterveer MH, Cen $\mathrm{Y}$, et al. The NAD+ precursor nicotinamide riboside enhances oxidative metabolism and protects against high-fat diet induced obesity. Cell Metab. 2012; 15: 838-47.

224. Araki T, Sasaki Y, Milbrandt J. Increased nuclear NAD biosynthesis and SIRT1 activation prevent axonal degeneration. Science. 2004; 305: 1010-3.

225. Sasaki Y, Araki T, Milbrandt J. Stimulation of nicotinamide adenine dinucleotide biosynthetic pathways delays axonal degeneration after axotomy. J Neurosci. 2006; 26: 8484-91.

226. Katsyuba E, Auwerx J. Modulating NAD+ metabolism, from bench to bedside. EMBO J. 2017; 36: 2670-83. 